\title{
A Modeling Study on the Impacts of Typhoon Morakot's (2009) Vortex Structure on Rainfall in Taiwan Using Piecewise Potential Vorticity Inversion
}

\author{
Chung-Chieh WANG, Kuan-Yu LIN \\ Department of Earth Sciences, National Taiwan Normal University, Taiwan \\ Christopher A. DAVIS \\ National Center for Atmospheric Research ${ }^{\#}$, Colorado, USA \\ Shin-Yi HUANG \\ Department of Earth Sciences, National Taiwan Normal University, Taiwan \\ Stefano Chih-Shin LIU \\ Research and Development Center, Central Weather Bureau, Taiwan \\ Kazuhisa TSUBOKI \\ Institute for Space-Earth Environmental Research, Nagoya University, Nagoya, Japan \\ and \\ Ben Jong-Dao JOU \\ Department of Atmospheric Sciences, National Taiwan University, Taiwan
}

(Manuscript received 18 August 2019, in final form 20 March 2020)

\begin{abstract}
In this study, the impacts of Typhoon Morakot's (2009) vortex structure on the extreme rainfall in Taiwan were investigated using piecewise potential vorticity (PV) inversion. The control (CTL) experiment, starting at 0000 UTC 7 August or $15 \mathrm{~h}$ before landfall, reproduced the event realistically and was validated against the observations. By altering the PV perturbation inside $750 \mathrm{~km}$ from its center, we conducted sensitivity experiments in which the size and circulation strength of TY Morakot were reduced/weakened in the initial field in several different ways.

In the sensitivity tests, particularly those in which the initial PV within the inner core $(\leq 250 \mathrm{~km})$ was significantly weakened, the storm made landfall earlier, stayed over land longer, and exited Taiwan later. Such track changes were accompanied by a contraction and spin-up of the inner core at the early stages of the integration,
\end{abstract}

Corresponding author: Shin-Yi Huang, Department of Earth

Sciences, National Taiwan Normal University. No. 88, Sec.

4, Ting-Chou Rd., Taipei, 11677 Taiwan

E-mail: hshinyi0828@gmail.com

\# The National Center for Atmospheric Research is sponsored by the National Science Foundation.

J-stage Advance Published Date: 20 April 2020

(C) The Author(s) 2020. This is an open access article published by the Meteorological Society of Japan under a Creative Commons Attribution 4.0 International (CC BY 4.0) license (https://creativecommons.org/licenses/by/4.0). 
caused by convection/latent heating within the inner core under large-scale, low-level southwesterly flow. As a result, Taiwan received an overall rainfall amount either comparable to or even more (up to $12 \%$ ) than that of the CTL in all tests. Thus, a weaker TY Morakot does not necessarily lead to less total rainfall over Taiwan, and the strong southwesterly flow and its moisture supply were bigger factors than the vortex structure in this event.

On the other hand, the rainfall in the southern Central Mountain Range on 8 August, which was the most-rainy area and period in reality, tended to decrease by up to $40 \%$ with the contraction and a weaker outer circulation. Thus, the rainfall patterns and evolution in the sensitivity tests were considerably different from those in CTL, indicating that the vortex structure plays a significant role in the rainfall in this region.

Keywords tropical cyclone; potential vorticity inversion; Typhoon Morakot (2009); cloud-resolving models; western North Pacific; Taiwan

Citation Wang, C.-C., K.-Y. Lin, C. A. Davis, S.-Y. Huang, S. C.-S. Liu, K. Tsuboki, and B. J.-D. Jou, 2020: A modeling study on the impacts of Typhoon Morakot (2009)'s vortex structure on rainfall in Taiwan using piecewise potential vorticity inversion. J. Meteor. Soc. Japan, 98, 707-733, doi:10.2151/jmsj.2020-036.

\section{Introduction}

Located in the main path of tropical cyclone (TC) activity over the western North Pacific, Taiwan is typically hit by several TCs each year. The most devastating event among them since 1959 was Typhoon (TY) Morakot that occurred on 7-9 August, which caused 757 deaths and estimated direct damages of USD 3.8 billion (Lee et al. 2011; Wang et al. 2012; Chang et al. 2013). With a 48-h-peak rainfall of 2361 $\mathrm{mm}$ in the Central Mountain Range (CMR) of Taiwan, only $132 \mathrm{~mm}$ less than the world record (Hsu et al. 2010; Wang et al. 2015), the destruction of TY Morakot (2009) was almost entirely caused by its extreme rainfall (e.g., Chanson 2010; also Hendricks et al. 2011). In particular, the rainfall triggered a major flash mudslide that caused majority of the deaths at around 2200 UTC 8 August in Shiao-Lin, a village in a river valley located in the southern CMR (SCMR; Wang et al. 2012, 2013b). After TY Morakot, many studies have been conducted to help understand how and why such extreme rainfall occurred (Hsu et al. 2010; Lee et al. 2011; Wu 2013).

As presented in Fig. 1, after its formation near $134^{\circ} \mathrm{E}$ on 3 August 2009, TY Morakot travelled westward, made landfall in Taiwan, and then turned northward on 8 August. This track change resulted from the interaction between TY Morakot and large-scale southwesterly wind surges associated with a monsoon gyre at intraseasonal timescales of both the quasibiweekly and Madden-Julian oscillations (Hong et al. 2010; Wu et al. 2011; Liang et al. 2011). As the background steering flow shifted from easterly to southerly, it weakened, and the translation speed of
TY Morakot decreased as it impacted Taiwan (also Chien and Kuo 2011; Huang et al. 2017). The 4000$\mathrm{km}$ cyclonic gyre (including two other TCs, Goni and Etau) at 0000 UTC 7 August 2009 and the associated southwesterly wind surge are well presented in Fig. 1 (also Nguyen and Chen 2011). Embedded inside the gyre, TY Morakot (2009) was very large in size, with a strong outer circulation at low levels, especially to its south (Fig. 1).

While the steering flow weakened to about 10 $\mathrm{km} \mathrm{h}^{-1}$, the mean translation speed of TY Morakot (2009) further decreased to about $5 \mathrm{~km} \mathrm{~h}^{-1}$ on 8 August upon its departure from Taiwan (cf. Fig. 1), when the rainfall in the SCMR was the heaviest (Wang et al. 2012, 2013b). This additional slow-down was attributed to the effect of asymmetric rainfall and, thus, latent heating that generated potential vorticity (PV) to the rear side of the TC motion during this period (Wang et al. 2012; Hsu et al. 2013). Recently, Chen et al. (2017) further demonstrated that it was the east-west rainband over the Taiwan Strait, rather than the north-south topographic rainband at the windward slopes of the SCMR, that contributed to the additional slow-down of TY Morakot during its departure.

Formed over the southern Taiwan Strait by the convergence between the (northwesterly) TC circulation and the southwesterly flow, the east-west rainband was persistent, and the convective cells, with frequent merging, enhancement, and back-building behaviors, were crucial factors that led to the flooding over the southwestern plains of Taiwan (e.g., Wang et al. 2010; Wang et al. 2015). Wang et al. (2015) studied the convective-scale interactions inside this rainband between the updrafts and vertical wind shear associated 
with the low-level westerly jet. They found that the induced dynamic pressure perturbations promote an enhancement of updrafts to the west (on the rear side of cell motion) and thus a slow-down of the mature cells and, subsequently, their merging with new cells and back-building behaviors.

Contrarily, the north-south topographic rainband was caused mainly by forced uplift of low-level flow by the steep terrain of the CMR (Ge et al. 2010; Fang et al. 2011; Huang et al. 2011; Xie and Zhang 2012; Yu and Cheng 2013; Hendricks et al. 2016). Obviously, the role played by the topography of Taiwan was not unique to TY Morakot, as noted previously on many occasions (e.g., Chang et al. 1993; Wu et al. 2002; Cheung et al. 2008), but the precipitation efficiency was particularly high in this case (Huang et al. 2014) with the moisture-rich southwesterly monsoon surge (Chien and Kuo 2011; Chen et al. 2017). Thus, a number of favorable factors from large to convective scales interacted together and worked in synergy to produce the extreme rainfall in TY Morakot (2009), where its slow translation speed and large size appear to be a deadly combination (cf. Fig. 1), given the abundant moisture supply and steep terrain of Taiwan.

Compared with the many factors reviewed above, the role played by the vortex size and structure of TY Morakot (2009) itself in the event was barely studied. Huang et al. (2011) employed the bogus data assimilation (BDA) method in a four-dimensional variational (4DVAR) analysis system (Zou et al. 1998; Zou and Xiao 2000) to generate a weak vortex for TY Morakot in the initial field of their sensitivity test using the fifth-generation Pennsylvania State University/National Center for Atmospheric Research (PSU/ NCAR) mesoscale model (MM5). In this experiment, which started at 0000 UTC 6 August 2009, the center of the weak vortex never made landfall in Taiwan and produced much less total rainfall. In other words, issues related to this aspect, such as what would happen if TY Morakot made landfall with a different size or vortex structure, have yet to be properly studied. While one might intuitively expect a smaller or weaker vortex to bring less rainfall to Taiwan, would this relationship hold true in a rather complicated case such as TY Morakot? Or how important is the role of vortex structure in comparison with other factors, such as the southwesterly flow? This study, therefore, aimed to address these questions and elucidate the role of TY Morakot's size and circulation structure on the rainfall in Taiwan using the PV inversion technique (PVIT) and a cloud-resolving model (CRM) for numerical experiments.
The remaining parts of this paper are arranged as follows. The data and research methodology, including the PVIT and the way it is used to alter the structure of the TC vortex in the initial field, the CRM, and the experiment design are described in Section 2. In Section 3 , the control simulation with TY Morakot unchanged is presented and validated against the observations. Then, our sensitivity test results for an initial vortex with a smaller size and weaker circulation are presented and compared in Section 4 and further discussed in Section 5. Finally, the conclusions and summary are provided in Section 6.

\section{Data and methodology}

\subsection{Data}

To verify the control simulation, the best-track data of TY Morakot (2009) from the Central Weather Bureau (CWB) of Taiwan, Japan Meteorological Agency (JMA), and Joint Typhoon Warning Center (JTWC) were used. Other observations include hourly rainfall data from about 400 gauge and reflectivity composites from land-based radars (every $30 \mathrm{~min}$ ). For all model experiments, the European Center for Medium-Range Weather Forecasts (ECMWF)-Year of Tropical Convection (YOTC) gridded analyses (e.g., Waliser et al. 2012; Moncrieff et al. 2012), available every $6 \mathrm{~h}$ on a $0.25^{\circ}$ latitude/longitude grid on 25 pressure $(p)$ levels (1000 to $1 \mathrm{hPa}$ ), were used as initial and boundary conditions (IC/BCs). To assist in the analysis of vortex structure, Quick Scatterometer (QuikSCAT) ocean surface winds were also used.

For the PV inversion, the ECMWF Tropical Ocean Global Atmosphere (TOGA) analyses on a $1.125^{\circ} \times$ $1.125^{\circ}$ grid on nine $p$-levels $(1000,925,850,700$, $500,400,300,200$, and $100 \mathrm{hPa}$ ), also every $6 \mathrm{~h}$, were used. Compared with the YOTC data, a reduction in resolution is required in practice for the solution to converge (e.g., Wang et al. 2016b). Additionally, to compute a mean PV field, a longer period is required. After some tests, it was chosen to be the time-mean of June-August 2009 to better exclude the slow-moving TY Morakot. Below, further details of the PV inversion, and how it is applied to modify the initial vortex structure of TY Morakot for sensitivity tests, are presented.

\subsection{Piecewise PV inversion}

First introduced by Ertel (1942), the PV $(q)$ is defined as $q=(1 / \rho)(\boldsymbol{\eta} \times \nabla \theta)$, where $\rho$ denotes air density; $\theta$, potential temperature; and $\boldsymbol{\eta}$ and $\boldsymbol{\nabla}$, threedimensional absolute vorticity vector and gradient operator, respectively. Based on its properties of con- 


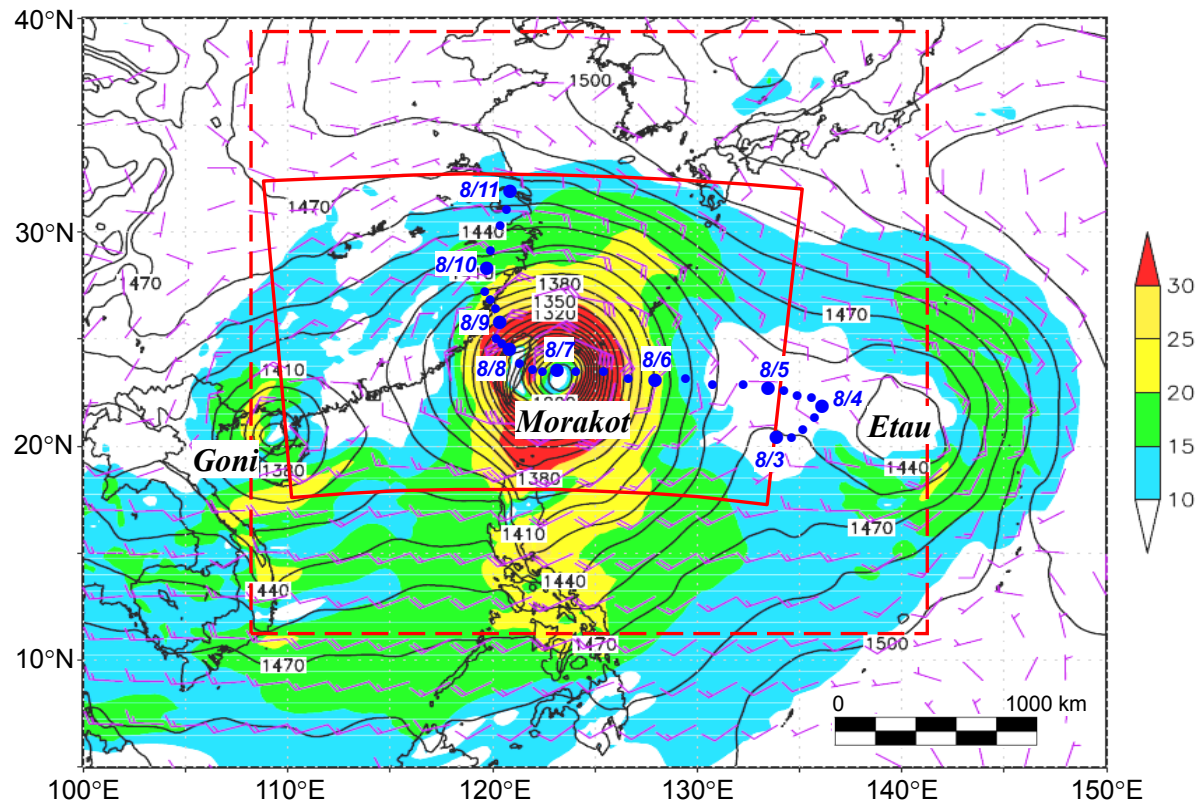

Fig. 1. The ECMWF-YOTC 850-hPa analysis of geopotential height (gpm, contours) and horizontal winds ( $\mathrm{m} \mathrm{s}^{-1}$, full barb $=10 \mathrm{~m} \mathrm{~s}^{-1}$ and half barb $=5 \mathrm{~m} \mathrm{~s}^{-1}$ ), with wind speed shaded (scale on the right) at 0000 UTC 7 August 2009. Three cyclones, Goni, Morakot, and Etau, are labeled. The JMA best track of TY Morakot is also depicted, with the center position given every $6 \mathrm{~h}$ from 0000 UTC 3 August to 0000 UTC 10 August (blue dots, enlarged and labeled at 0000 UTC of each day). The red dashed box indicates the region of PV inversion, and the red solid lines indicate the model simulation domain.

servation (for dry adiabatic motion) and invertibility (e.g., Hoskins et al. 1985), Davis and Emanuel (1991) and Davis (1992a) developed a piecewise PVIT under a nonlinear-balanced dynamical constraint (Charney 1955), and the method has been widely used for the diagnoses of various weather systems (e.g., Davis et al. 1996; Shapiro 1996; Chang et al. 1998; Morgan 1999; McTaggart-Cowan et al. 2001; Chen et al. 2003, 2008).

With a proper mean (or background) PV field $\left(q_{m}\right)$ and BCs, the total PV perturbation $q^{\prime}\left(=q-q_{m}\right)$ and any of its user-defined component can be isolated and quantified through piecewise PV inversion (Davis 1992a, b), with an advantage that the superposition principle holds (i.e., the solutions to each component would add up to the total $q^{\prime}$ ). Moreover, these "pieces" of $q^{\prime}$ are linear and can be altered and inverted back to provide the corresponding mass and wind field perturbations; this was the property applied to modify the TC vortex structure in the present study. Here, the $\mathrm{PV}$ inversion domain is set to $11.25-39.375^{\circ} \mathrm{N}, 108-$ $141.75^{\circ} \mathrm{E}$, and the part of $q^{\prime}$ in a cylindrical volume within $750 \mathrm{~km}$ from the TC center and at 1000-100 $\mathrm{hPa}$ (cf. Fig. 1) is what will be altered. Thus, nothing is changed outside the $750-\mathrm{km}$ radius or above 100 $\mathrm{hPa}$. Here, $q_{m}$ is set to be the average of 1 June-30 August of 2009, and as in Chen et al. (2003, 2006, and 2008), the lateral BCs are observed geopotential $\boldsymbol{\Phi}$ and streamfunction $\boldsymbol{\Psi}$ for the total field and $\boldsymbol{\Phi}^{\prime}=$ $\Psi^{\prime}=0$ for perturbations. The top and bottom BCs are $\partial \boldsymbol{\Phi} / \partial \pi=f_{0}(\partial \boldsymbol{\Psi} / \partial \pi)=-\theta$ (where $\pi$ denotes the Exner function; $f_{0}$, the Coriolis parameter at reference latitude; and $\theta$, the potential temperature) for the total field and $\partial \boldsymbol{\Phi}^{\prime} / \partial \pi=f_{0}\left(\partial \boldsymbol{\Psi}^{\prime} / \partial \pi\right)=-\theta^{\prime}$ for perturbations. Further details on the piecewise PVIT can be found in the above references.

\subsection{Modification of initial vortex structure}

Although the piecewise PVIT can provide the mass and wind fields associated with a modified PV structure (from $q_{m}+q^{\prime \prime}$, where $q^{\prime \prime}$ denotes an altered $q^{\prime}$ ), the nonlinear-balanced condition is not suitable for TCs, in which significant imbalance and inflow/outflow often exist at the lower and upper levels (e.g., Smith and Montgomery 2016). Therefore, instead of directly applying the results of PV inversion, the differences in inversions with unaltered and altered $q^{\prime}$ were used to provide information on how the vortex structure 

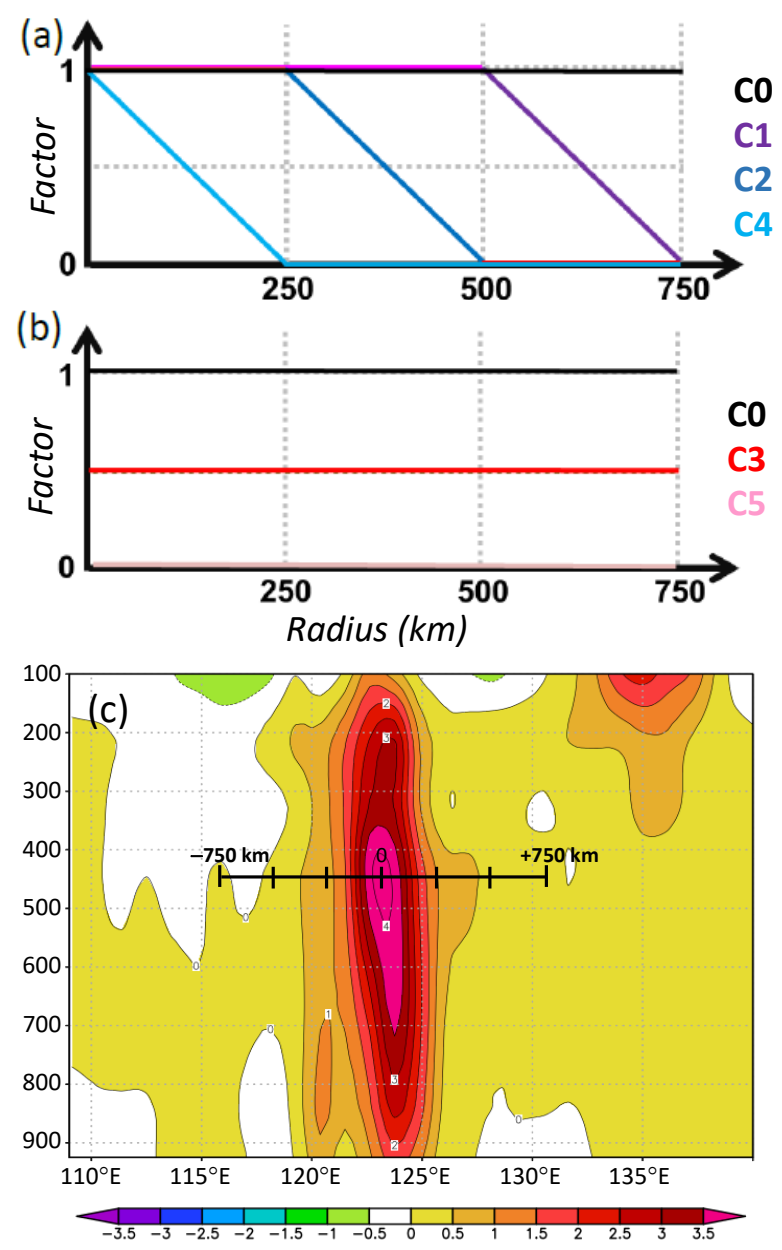

Fig. 2. Schematics to change the PV perturbation (fraction, 0 to 1) with respect to radius $(\mathrm{km})$, from the center of TY Morakot to $750 \mathrm{~km}$, in the initial fields of the control simulation $(\mathrm{C} 0)$ and sensitivity tests (C1 to $\mathrm{C} 5$ ). (a) Experiments $\mathrm{C} 0, \mathrm{C} 1, \mathrm{C} 2$, and $\mathrm{C} 4$ and $(\mathrm{b})$ experiments $\mathrm{C} 0$, $\mathrm{C} 3$, and C5. (c) East-west vertical cross section of PV perturbation (PVU, contoured every 0.5 PVU, scale at the bottom) through the center of TY Morakot at 0000 UTC 7 August 2009 in the ECMWF-TOGA data, with a range of $750 \mathrm{~km}$ depicted. The abscissa is the longitude $\left({ }^{\circ} \mathrm{E}\right)$, and the ordinate is the pressure $(\mathrm{hPa})$.

should be changed. Here, a total of six cases were designed to reduce the $q^{\prime}$ within $r=750 \mathrm{~km}$ (Fig. 2), where $\mathrm{C} 0$ corresponds to the unaltered $q^{\prime}$ (fixed at 100 $\%$ ) and, thus, the control (CTL) simulation. All other experiments conducted were sensitivity tests to gradually reduce the size of TY Morakot from C1, $\mathrm{C} 2$, to $\mathrm{C} 4$ (Fig. 2a) and its vortex strength by a fixed

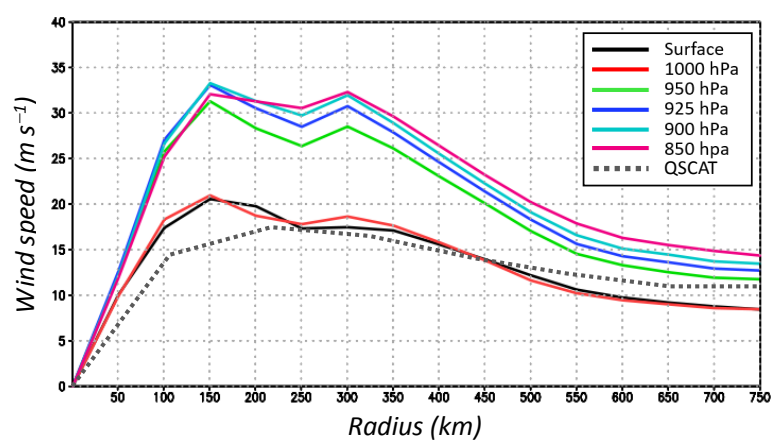

Fig. 3. The azimuthally averaged (axisymmetric) wind speed $\left(\mathrm{m} \mathrm{s}^{-1}\right)$ computed from the ECMWFYOTC analysis at different levels from the surface to $850 \mathrm{hPa}$ (solid curves) at 0000 UTC 7 August 2009 and from the QSCAT data (dotted gray curve) at 1200 UTC 6 August 2009.

percentage in $\mathrm{C} 3\left(q^{\prime \prime}=50 \%\right.$ of $\left.q^{\prime}\right)$ and C5 $\left(q^{\prime \prime}=0 \%\right.$ of $q^{\prime}$, Fig. 2b). The experiment names $\mathrm{C} 1$ to $\mathrm{C} 5$ were designated, such that their $q^{\prime}$ changed from strong to weak to facilitate later discussion. In Fig. 2c, the total $q^{\prime}$ in the east-west vertical cross section through the TC center at the model initial time $\left(t_{0}\right.$, at 0000 UTC 7 August 2009) is presented to concentrate mainly within $250 \mathrm{~km}$, with a peak anomaly of about 4.5 PVU (where 1 PVU $=10^{-6} \mathrm{~K} \mathrm{~m}^{2} \mathrm{~kg}^{-1} \mathrm{~s}^{-1}$ ) near 450 $\mathrm{hPa}$. Corresponding to this PV structure, the azimuthally averaged wind speed distributions computed from the ECMWF-YOTC analysis and QuikSCAT data (the latter at 1200 UTC 6 August) indicate a radius of maximum wind (RMW) of about 150-200 km near the surface (Fig. 3), consistent with the studies by Wang et al. (2012, 2013b) and Chen et al. (2017). Thus, the eye region of TY Morakot is very large and atypical among most TCs.

Let $\mathbf{v}_{B 0}=\left(u_{B 0}, v_{B 0}\right)$ be the balanced wind from unaltered $q^{\prime}$ in $\mathrm{C} 0$ (inverted from $q_{m}+q^{\prime}$ ) and $\mathbf{v}_{B n}$ be that from an altered $q^{\prime}$ in the $n$th case $(n \in 1-5$, e.g., $n=3$ for C3; inverted from $q_{m}+q^{\prime \prime}$ based on Fig. 2), both in the ECMWF-TOGA data. A nondimensional fractional factor $F_{v}$ (bounded by 0 and 1) at each grid point inside $r=750 \mathrm{~km}$ at each level is obtained using the below equation:

$$
F_{v}(x, y, p)=\left|\mathbf{v}_{B n}(x, y, p)\right| /\left|\mathbf{v}_{B 0}(x, y, p)\right|,
$$

where the subscript $v$ denotes the wind; therefore, $F_{v}$ is simply the wind speed fraction of the reduced to non-reduced case from the inversion. This factor was then linearly interpolated onto the ECMWF-YOTC grid both horizontally and vertically to construct the 
new wind field for the $n$th case. Thus, only the wind speed was altered (reduced), and the inflow/outflow angle remained the same (including that in the boundary layer) to retain an unbalanced portion of the flow in the analysis. Since both the rotational and divergent components of the flow were reduced by the same fraction, the primary and transverse circulations of the vortex weakened in a consistent way. This method also takes advantage of the high resolution of the YOTC data for model experiments.

For geopotential height $(z)$ inside $r=750 \mathrm{~km}$, the fractional factor $F_{z}$ between the two balanced cases is defined as

$$
F_{z}(x, y, p)=D_{B n}(x, y, p) / D_{B 0}(x, y, p),
$$

where $D_{B}$ denotes the deficit in $z$ at the grid point from the mean value at the perimeter (at $r=750 \mathrm{~km}$ ) in the balanced fields, such that $\overline{D_{B}}=z_{B, 750 \mathrm{~km}}(p)-$ $z_{B}(x, y, p)$. After interpolation, this fraction (again, $\left.0 \leq F_{z} \leq 1\right)$ was also applied to the YOTC data to construct the geopotential height field for the $n$th case accordingly, where the new $z$ (within $r=750 \mathrm{~km}$ ) is

$$
\begin{aligned}
z_{\mathrm{YOTC}}(x, y, p)= & \bar{z}_{\mathrm{YOTC}, 750 \mathrm{~km}}(p) \\
& -F_{z}(x, y, p) \cdot D_{\mathrm{YOTC}}(x, y, p) .
\end{aligned}
$$

Note that since the balanced fields in $\mathrm{C} 0$ served as the reference (and $F_{v}=F_{z}=1$ everywhere), neither $\mathbf{v}$ nor $z$ was changed in the YOTC data, so $\mathrm{C} 0$ was essentially the CTL. Next, at grid points where the thickness $\Delta z$ has been changed in the YOTC data (in the $n$th case), the temperature ( $T$ ) was adjusted based on the hypsometric relationship, such that the adjustment $(\Delta T)$ is

$$
\Delta T(x, y, p) \approx\left(g / R_{d}\right) \cdot \Delta z / \ln \left(p_{k-1} / p_{k+1}\right),
$$

where $g$ denotes gravitational acceleration; $R_{d}$, the gas constant; $k-1$, the level below; and $k+1$ the level above the current $p$-level, whereas $\Delta z$ is the change in thickness between the two levels $(k+1$ and $k-1)$ in the $n$th case compared with $\mathrm{C} 0$. Thus, a thinner layer $(\Delta z<0)$ corresponds to a cooler temperature $(\Delta T<0)$. To prevent strong discontinuity near $r=750 \mathrm{~km}$, a nine-point smoothing technique was applied twice within the radius range of $625-812.5 \mathrm{~km}$ for $\mathbf{v}, z$, and $T$. Finally, the moisture field was unaltered and identical in all cases, with only two exceptions: 1) to remove excessive water vapor beyond saturation in regions where $T$ has been reduced to below dew (or frost) point by Eqs. (4) and (2) in the additional test of $\mathrm{C} 3 \mathrm{~A}$, which will be explained later in Section 5c.

Using the above procedure, new initial fields were constructed from the YOTC data individually at 0000
UTC 7 August for $\mathrm{C} 1$ to $\mathrm{C} 5$ based on Figs. 2a, b. These fields in $\mathrm{C} 0$ (or CTL) and $\mathrm{C} 1-\mathrm{C} 5$ at $850 \mathrm{hPa}$ are presented in Fig. 4, where the flow associated with TY Morakot retains its asymmetry and is not necessarily parallel to height contours, indicative of unbalanced wind components as designed, and the fields outside $r=750 \mathrm{~km}$ are identical among all experiments (except for small differences due to smoothing). Note, however, that even though the discontinuity appeared significant near $750 \mathrm{~km}$ in $\mathrm{C} 3-\mathrm{C} 5$, it was only in wind speed that corresponded to high inertial stability (similar to the conditions at the inner core). In Fig. 5, the radius-height sections of the azimuthally averaged vortex structures in $\mathrm{C} 0-\mathrm{C} 5$ at $t_{0}$ are presented for comparison. Note that the RMW near $1.5 \mathrm{~km}$ in $\mathrm{C} 0$ is close to $250 \mathrm{~km}$, inside which the region can be considered the inner core. Also, when $q^{\prime}$ is significantly reduced in the inner core (in $\mathrm{C} 3$ to $\mathrm{C} 5$ ), the eye in the IC shrinks in size as well.

\subsection{The cloud-resolving storm simulator model and experiments}

The Cloud-Resolving Storm Simulator (CReSS) model (Tsuboki and Sakakibara 2002, 2007), a nonhydrostatic and compressible cloud model with a terrain-following vertical coordinate and a single domain (without nesting), was used in this study for all experiments. The version (2.3) is identical to those in the studies by Wang (2015) and Wang et al. (2012, $2013 \mathrm{~b}, 2015,2016 \mathrm{a}, \mathrm{c})$, so the readers are referred to the references therein, and only a brief description is provided below. In CReSS, clouds are explicitly treated using a bulk cold-rain microphysics scheme (six species: vapor, cloud water, cloud ice, rain, snow, and graupel) with no cumulus parameterization, whereas parameterized subgrid-scale processes include turbulent mixing in the boundary layer, surface radiation, and momentum/energy fluxes (Table 1).

As described in Section 2c, the C0 (or CTL) experiment used the $0.25^{\circ} \mathrm{ECMWF-YOTC}$ analyses directly as the IC/BCs to reproduce the event from 0000 UTC 7 to 0000 UTC 10 August 2009 (Table 1). At the lower boundary, terrain data at a 30" resolution (roughly 900 $\mathrm{m}$ ) and the analyzed sea surface temperature (Reynolds et al. 2002) were also provided. All the sensitivity tests used identical settings, except for the modified YOTC data with an altered TC vortex structure within $r=750 \mathrm{~km}$ in the IC (Fig. 2, Table 1). Since the entire TC was already inside the model domain at $t_{0}$ (cf. Fig. 1), the BCs after 0000 UTC 7 August did not need to be altered, and the YOTC data were used for all the runs. The tests of $\mathrm{C} 1-\mathrm{C} 5$, therefore, can be compared 

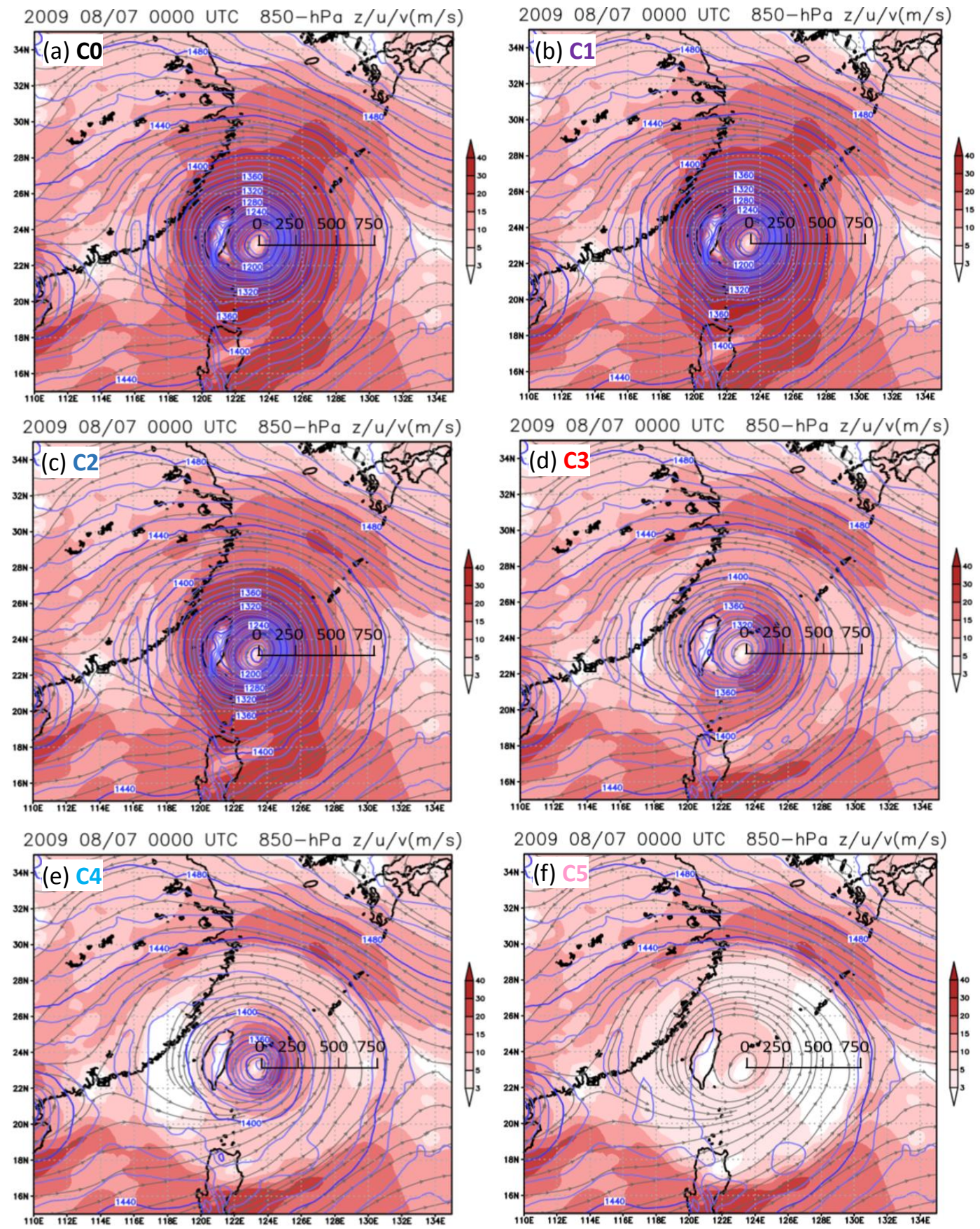

Fig. 4. The 850-hPa initial fields (at 0000 UTC 7 August 2009) of geopotential height (gpm, blue contours every 10 gpm, thickened every four lines), streamlines (gray), and wind speed ( $\mathrm{m} \mathrm{s}^{-1}$, color) from the ECMWF-YOTC analysis used in experiments (a) $\mathrm{C} 0$ to (f) $\mathrm{C} 5$, respectively. A distance out to $750 \mathrm{~km}$ from the TC center is also labeled.

with the CTL to show the impacts of the different initial vortex structures of TY Morakot (2009) on the rainfall in Taiwan. Before that, the CTL needs to be validated against observations, and this is presented in the next section. 
(a) $\mathrm{CO}$

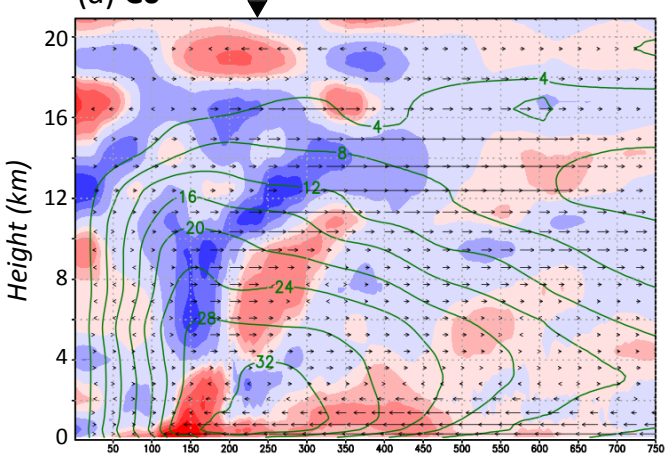

(c) $\mathrm{C} 2$

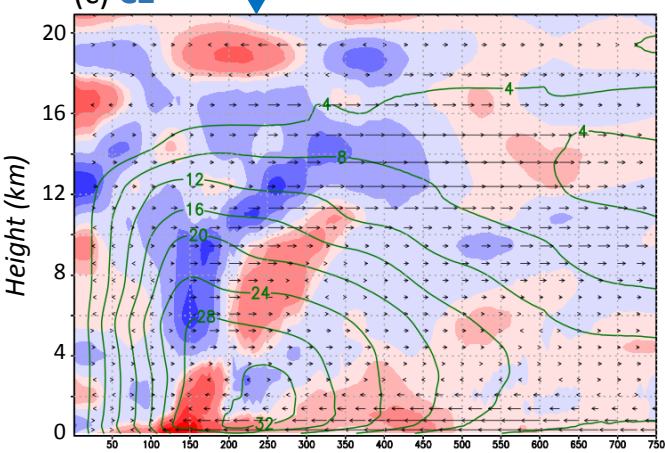

(e) $\mathrm{C} 4$

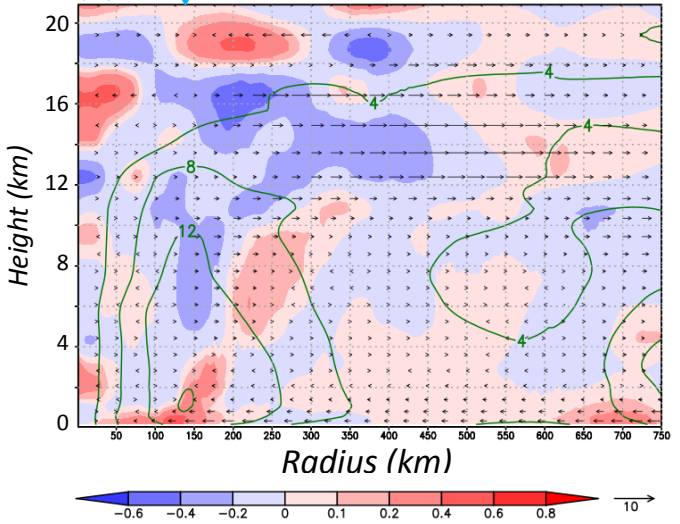

(b) $\mathrm{C} 1$

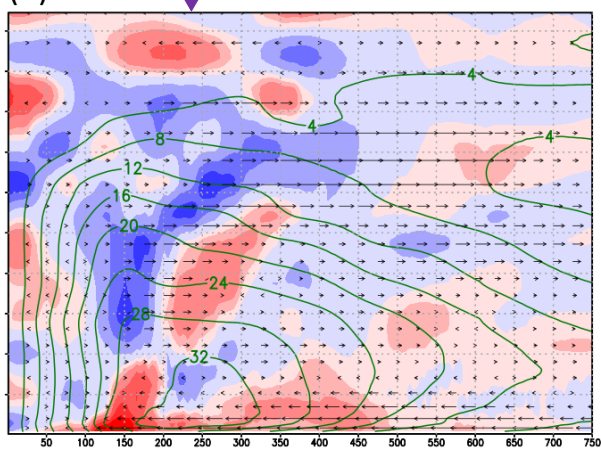

(d) C3

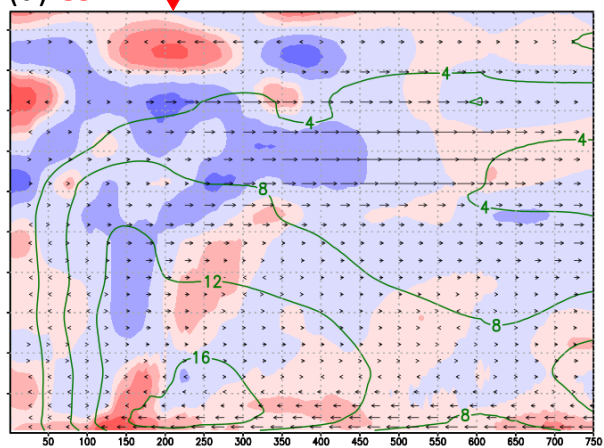

(f) $\mathrm{C} 5 \mathrm{~V}$

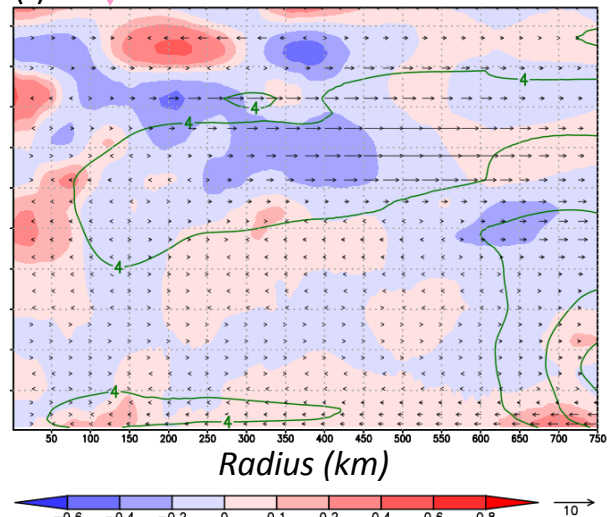

Fig. 5. Radius-height profiles of azimuthally averaged (axisymmetrical) tangential wind ( $\mathrm{m} \mathrm{s}^{-1}$, green isotachs, every $4 \mathrm{~m} \mathrm{~s}^{-1}$ ), radial wind ( $\mathrm{m} \mathrm{s}^{-1}$, horizontal vectors, reference length at bottom), and convergence/divergence fields ( $10^{-4}$ $\mathrm{s}^{-1}$, color, scale at the bottom, positive for convergence) at the initial time (at 0000 UTC 7 August 2009) of experiments (a) $\mathrm{C} 0$ to (f) $\mathrm{C} 5$, respectively, out to a distance of $750 \mathrm{~km}$ from the TC center. The triangle at the top of the panels marks the RMW near $1.5 \mathrm{~km}$.

\section{Control simulation and verification}

In the previous studies of Wang et al. (2012, 2013b, 2015) and Chen et al. (2017) on TY Morakot (2009), control experiments were also conducted using CReSS and validated against observations. Starting from 0000 UTC 7 August for 3 days, the CTL here was quite similar to those experiments, and its TC track and intensity were compared with the best-track data in Fig. 6. When crossing Taiwan, the northward turn of TY Morakot from a westward motion and its slow translation speed, especially during 0000-1200 UTC 8 August (at $<5 \mathrm{~km} \mathrm{~h}^{-1}$, e.g., Wang et al. 2012), were both well reproduced in CTL, with a track error within 
Table 1. The CReSS model domain configuration (top), boundary conditions (middle), and physical schemes (bottom) used in CTL simulation (C0) and sensitivity tests (C1-C8 and $\mathrm{C} 3 \mathrm{~A})$ in this study.

\begin{tabular}{|c|c|}
\hline Experiments & Sensitivity tests $\left(\mathrm{C} 1-\mathrm{C} 8, \mathrm{C} 3 \mathrm{~A}^{\#}\right)$ \\
\hline Projection & Lambert conformal, center at $120^{\circ} \mathrm{E}$, secant at $10^{\circ} \mathrm{N}$ and $40^{\circ} \mathrm{N}$ \\
\hline Grid spacing $(\mathrm{km})$ & $2.5 \times 2.5 \times 0.1-0.745(0.5)^{*}$ \\
\hline $\begin{array}{l}\text { Grid dimension }(x, y, z) \\
\text { and domain size }(\mathrm{km})\end{array}$ & $960 \times 640 \times 50(2400 \times 1600 \times 25)$ \\
\hline Initial condition (IC) & $\begin{array}{l}\text { ECMWF-YOTC analyses, } \\
\text { modified following Section } 2 \mathrm{c}\end{array}$ \\
\hline Initial time & 0000 UTC 7 Aug 2009 \\
\hline Boundary condition (BC) & ECMWF-YOTC analyses (every 6 h) \\
\hline Integration length & $72 \mathrm{~h}$ \\
\hline SST and topography & Weekly mean SST $\left(1^{\circ} \times 1^{\circ}\right)$, real at $(1 / 120)^{\circ}$ \\
\hline Output frequency & $30 \mathrm{~min}$ \\
\hline Cloud microphysics & $\begin{array}{l}\text { Bulk cold-rain (Lin et al. 1983; Cotton et al. 1986; Murakami 1990; } \\
\text { Ikawa and Saito 1991; Murakami et al. 1994) }\end{array}$ \\
\hline $\mathrm{PBL} /$ turbulence & $\begin{array}{l}\text { 1.5-order closure with prediction of turbulent kinetic energy } \\
\text { (Deardorff 1980; Tsuboki and Sakakibara 2007) }\end{array}$ \\
\hline Surface processes & $\begin{array}{l}\text { Energy/momentum fluxes, shortwave and longwave radiation } \\
\text { (Kondo 1976; Louis et al. 1981; Segami et al. 1989) }\end{array}$ \\
\hline Substrate model & 43 levels, every $5 \mathrm{~cm}$ to $2.1 \mathrm{~m}$ \\
\hline
\end{tabular}

about $60 \mathrm{~km}$ during the entire 3-day simulation period (Fig. 6a, Table 2). For intensity (Fig. 6b), the surface maximum wind in the model increased from about 32 to $40 \mathrm{~m} \mathrm{~s}^{-1}$, and the central sea-level pressure (SLP) dropped to $960 \mathrm{hPa}$ after $t_{0}$, both close to the observed peak values. After crossing Taiwan, the TC gradually weakened on 8-9 August. While the early intensification was a common response in high-resolution CRMs, the general behavior of the storm was similar to the experiment by Wang et al. (2012, cf. their Fig. 9). Even though the CTL produced a stronger maximum wind from about 1200 UTC 7 to 0000 UTC 9 August compared with the best-track data (Fig. 6b), the overall simulation of TC intensity in CTL was deemed reasonable.

Figure 7 compares the radar reflectivity composites in Taiwan every $12 \mathrm{~h}$ (except for 0600 UTC 7 August) with the column-maximum mixing ratio of precipitating hydrometeors (rain, snow, plus graupel) in CTL. Although the two variables are not the same, they are both vertical maxima, and the former is the return signal mainly from the latter. While the land-based radars cannot pick up low-level precipitation farther away from Taiwan, the comparison indicates that the CTL captures quite well the asymmetric rainfall structure of TY Morakot (mainly in the southern quadrants) and its associated rainbands throughout the simulation (Fig. 7). Also, there is a lack of a robust eyewall inside about $200 \mathrm{~km}$ in both the observation and CTL experiment in Fig. 7, in agreement with Fig. 3.

The observed and model-simulated total rainfall distributions in Taiwan over 7-9 August 2009, as well as the accumulations on each day individually, are compared in Fig. 8. From the gauge network (Fig. 8a), the observed 72-h peak rainfall was $2748 \mathrm{~mm}$ (cf. Wang et al. 2015) with the most rainfall in the SCMR and significant values (at least about $1000 \mathrm{~mm}$ ) near the intersection of the CMR and Snow Mountain Range (SMR) and over southwestern Taiwan (Fig. $8 \mathrm{~b})$. By comparison, the model yielded a peak amount of over $3000 \mathrm{~mm}$ but somewhat less rainfall in the southwestern plains, with an otherwise very similar spatial distribution (Fig. 8c). The rainfall patterns on each day of 7-9 August in the CTL (Figs. 8g-i) also resemble those observed (Figs. 8d-f), with the highest daily rainfall (of about $1560 \mathrm{~mm}$ ) recorded on 

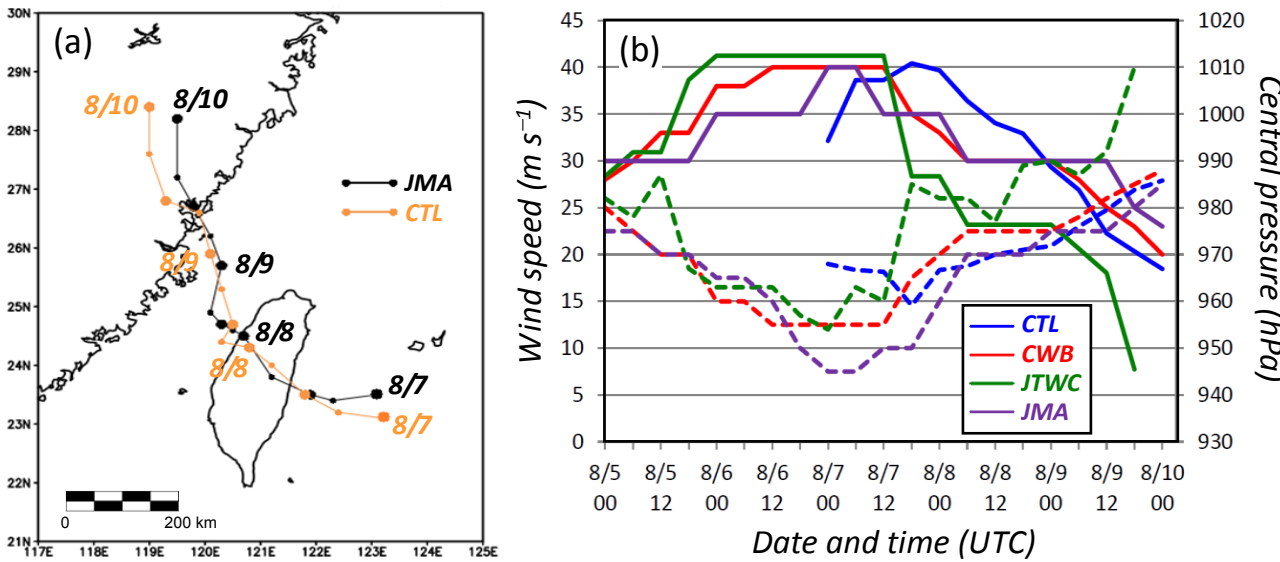

Fig. 6. (a) Comparison of simulated track of TY Morakot in CTL with the JMA best track over the period of 0000 UTC 7-10 Aug 2009, with the TC center position given every $6 \mathrm{~h}$ (enlarged at 0000/1200 UTC and labeled at 0000 UTC of each day). (b) Comparison of the maximum wind speeds ( $\mathrm{m} \mathrm{s}^{-1}$, solid) and minimum sea-level pressure (hPa, dashed) in CTL with those in CWB, JTWC, and JMA best-track data.

Table 2. Comparison of mean translation speed $\left(\mathrm{km} \mathrm{h}^{-1}\right)$ of TY Morakot (2009) during 12-h periods between JMA best track and CReSS simulation in CTL.

\begin{tabular}{lcc}
\hline \multicolumn{1}{c}{ Time period } & $\begin{array}{c}\text { JMA best } \\
\text { track }\end{array}$ & $\begin{array}{c}\text { Control } \\
\text { simulation } \\
\text { (CTL) }\end{array}$ \\
\hline 0000-1200 UTC 7 Aug & 10.2 & 12.5 \\
1200 UTC 7-0000 UTC 8 Aug & 13.7 & 11.3 \\
0000-1200 UTC 8 Aug & 3.8 & 4.5 \\
1200 UTC 8-0000 UTC 9 Aug & 9.3 & 11.6 \\
0000-1200 UTC 9 Aug & 10.2 & 10.7 \\
1200 UTC 9-0000 UTC 10 Aug & 14.1 & 15.0 \\
\hline
\end{tabular}

8 August upon the departure of TY Morakot (Wang et al. 2012; Chen et al. 2017). Over the SCMR (near $\left.22.3-22.7^{\circ} \mathrm{N}\right)$, the model appeared to produce more rain than observed, but this might be linked to an issue of undersampling, since very few rain gauges are installed in this remote mountainous area, as discussed by Wang et al. (2012).

For the most-rainy region of the SCMR, the average rainfall inside the rectangular box of $22.5-23.5^{\circ} \mathrm{N}$, $120.5-121.0^{\circ} \mathrm{E}$ (cf. Fig. 8a) was computed at 1-h intervals, and the histograms over 7-9 August in the observations and CTL are compared in Fig. 9. For this area of $1^{\circ}$ latitude $\times 0.5^{\circ}$ longitude, the model was observed capturing the rainfall evolution quite well, with the most intense rainfall occurring mainly on 8 August when TY Morakot was leaving Taiwan, as observed (Fig. 9, red bars). In order to compare the rainfall evolution more objectively, the three track phases of landfalling typhoons, as defined by Chang et al. (2013), were adopted (also Chen et al. 2017): the pre-landing (PR) phase when the TC center moves to within $100 \mathrm{~km}$ from the nearest coastline till landfall, the overland (OL) phase when the TC center passes through the island, and the exit (EX) phase when the $\mathrm{TC}$ center exits the land until a distance of $100 \mathrm{~km}$ away from the coast. Using these criteria, the PR and OL phases started at 0700 and 1500 UTC 7 August, respectively, in both the observations and CTL (cf. Fig. 6a), whereas the EX phase in CTL (lasting for 16 h) started $1 \mathrm{~h}$ later and ended $2 \mathrm{~h}$ earlier than its counterpart in the observations (Fig. 9). Nevertheless, the rainfall evolution over the SCMR in CTL compares favorably with the observations and, thus, is highly realistic, linked to the success in track simulation.

\section{Sensitivity tests}

As mentioned, two sets of sensitivity tests were designed to gradually change the IC (Fig. 2). The first set was conducted to reduce the size of TY Morakot, with its $q^{\prime}$ fixed at $100 \%$ out to a radius of $500 \mathrm{~km}$, then decreased linearly to $0 \%$ at $750 \mathrm{~km}$ in $\mathrm{C} 1$; out to $250 \mathrm{~km}$, then decreased to $0 \%$ at $500 \mathrm{~km}$ and beyond in $\mathrm{C} 2$; and decreased linearly from $100 \%$ at the TC center to $0 \%$ at $250 \mathrm{~km}$ and beyond in $\mathrm{C} 4$ (Fig. 2a). The second set (Fig. 2b) was conducted to reduce TY Morakot's circulation strength by a fixed percentage at $0-750 \mathrm{~km}$ : with $q^{\prime}$ cut to $50 \%$ in $\mathrm{C} 3$ and $0 \%$ in $\mathrm{C} 5$, which is intended to completely remove the $q^{\prime}$ associ- 

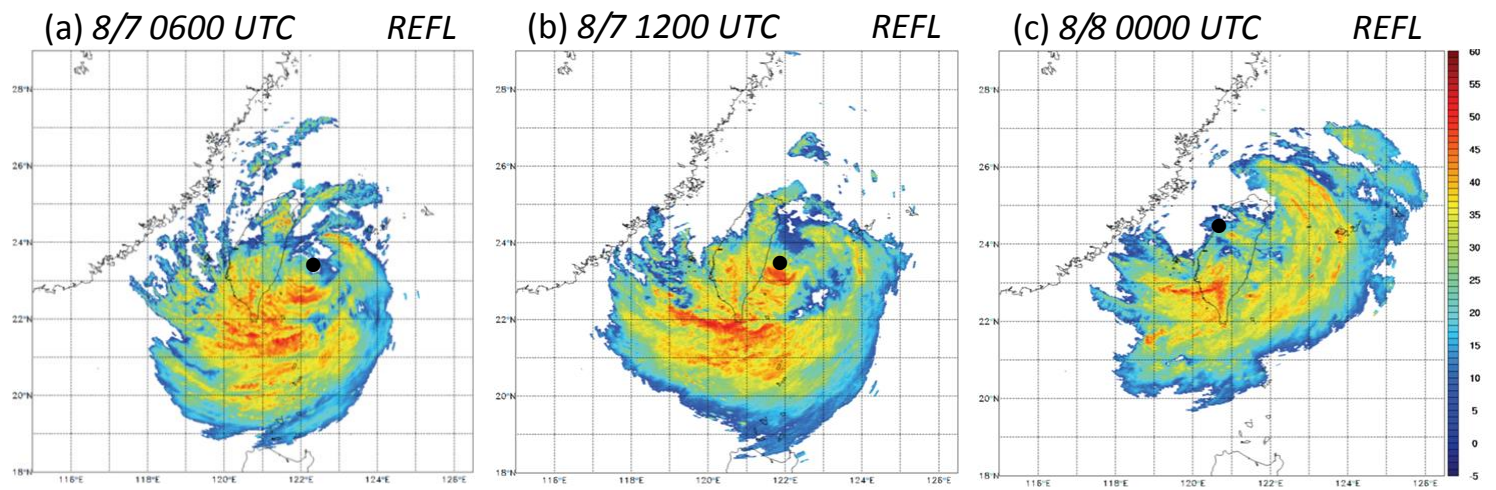

(d) $8 / 81200$ UTC REFL
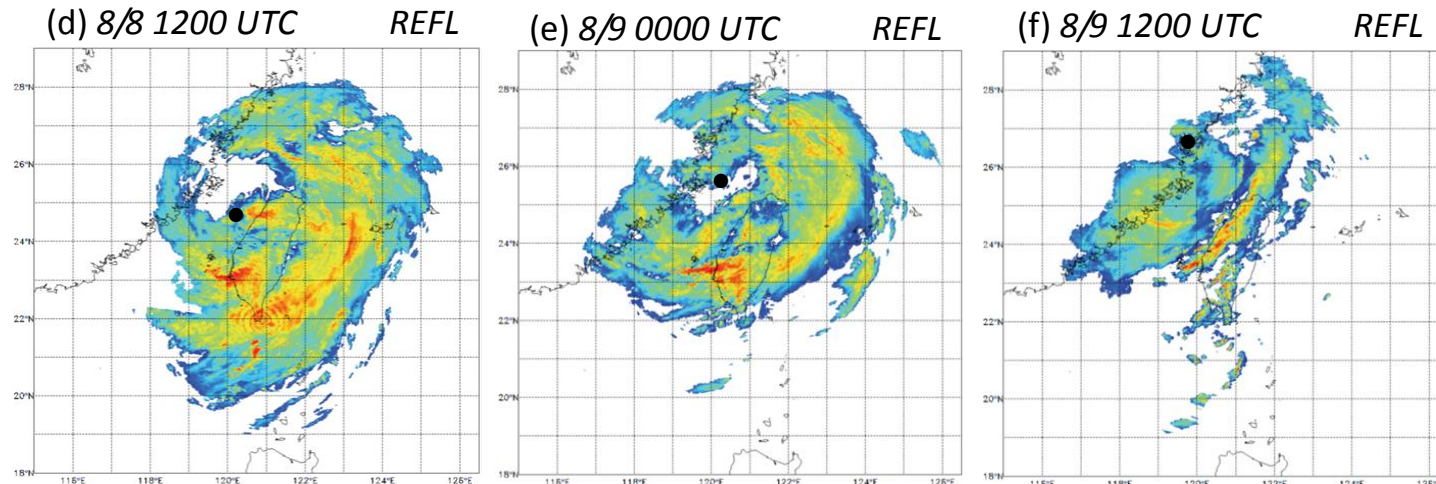

(g) 8/70600 UTC CTL-MPR
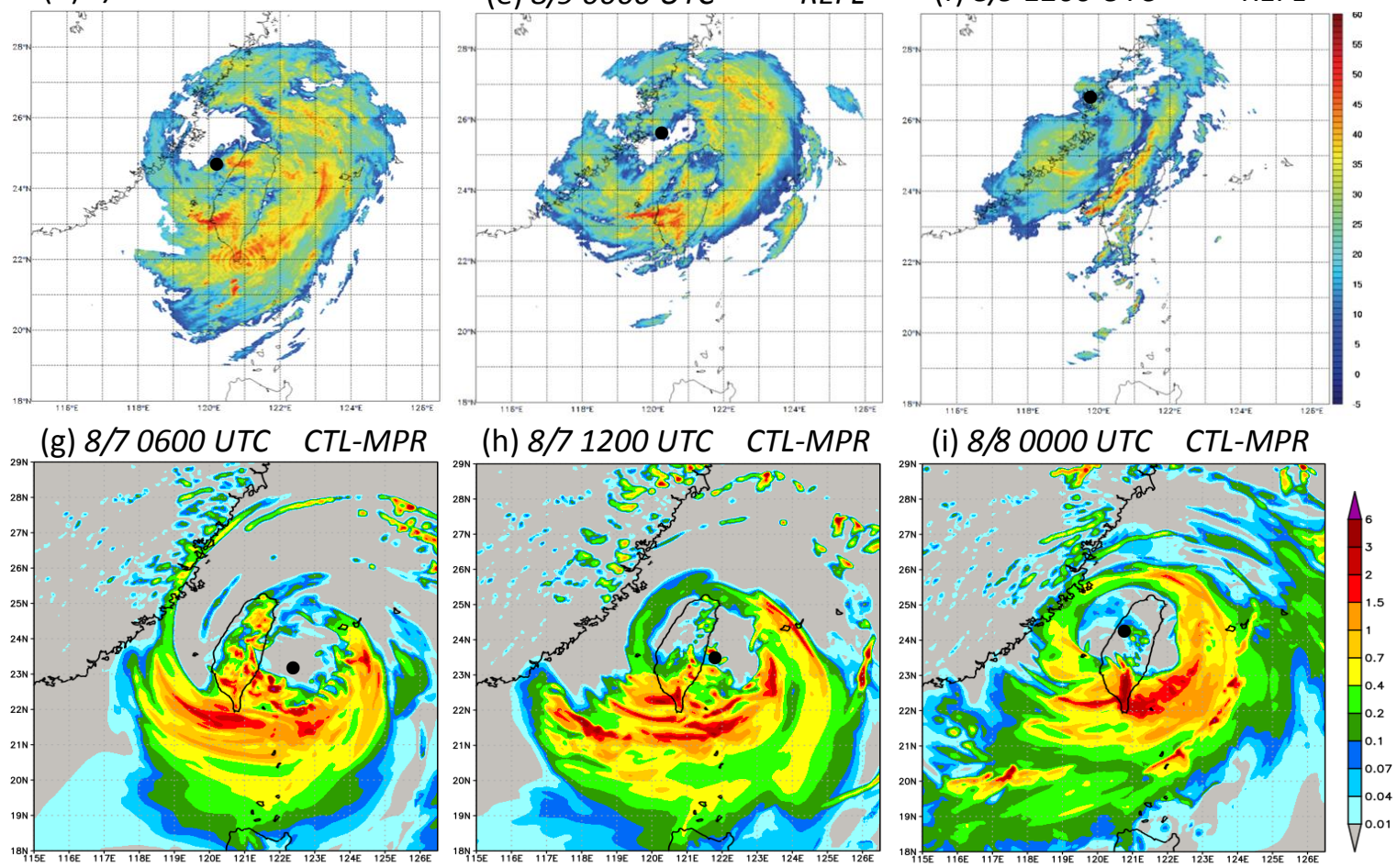

(j) $8 / 81200$ UTC CTL-MPR
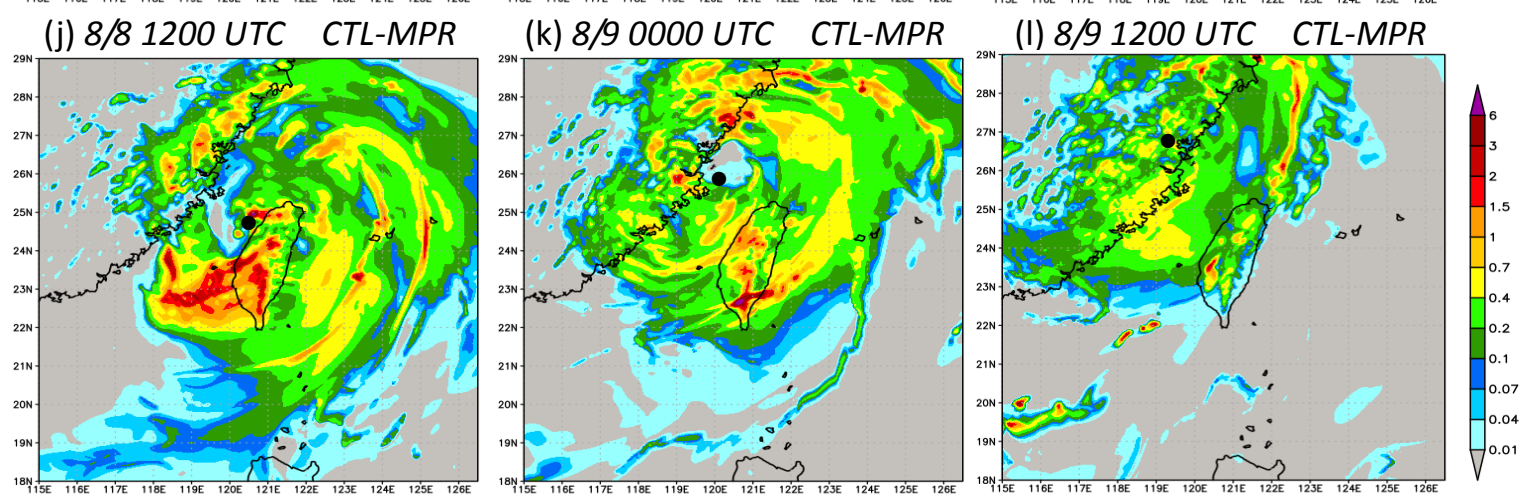

Fig. 7. (a)-(f) Radar reflectivity composite (dBZ, scale on the right) over the Taiwan area at (a) 0600 UTC 7 August and every $12 \mathrm{~h}$ from (b) 1200 UTC 7 August to (f) 1200 UTC 9 August 2009. (g)-(l) Model simulation of columnmaximum mixing ratio of precipitation $\left(\mathrm{g} \mathrm{kg}^{-1}\right.$, rain + snow + graupel, scale on the right $)$ in CTL at the same times as in (a)-(f). The solid dots mark the TC center. 

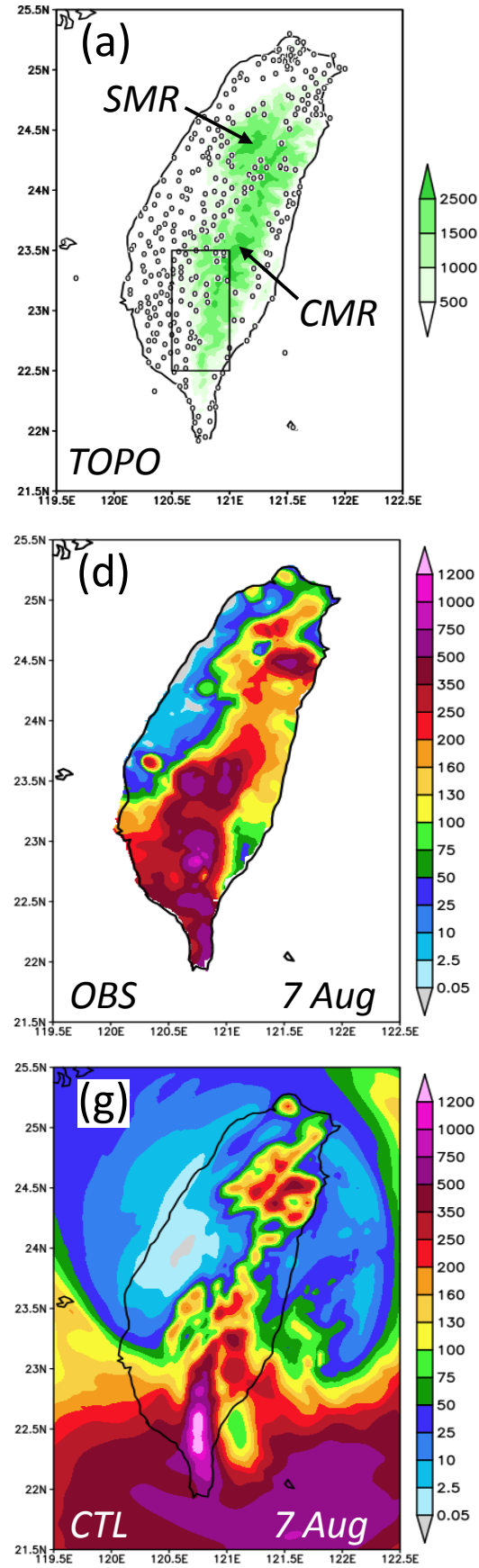
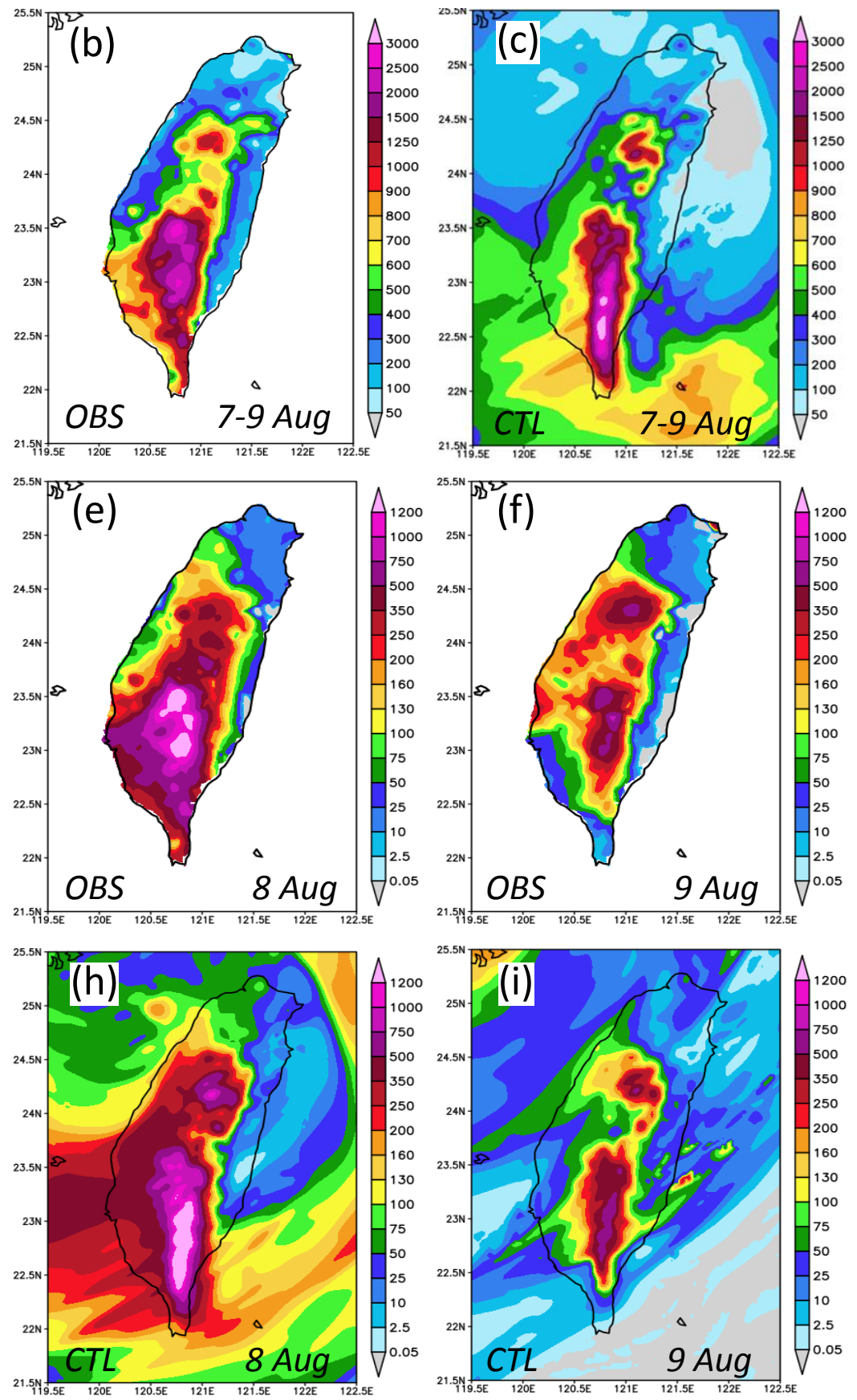

Fig. 8. (a) Topography of Taiwan (m) and distribution of rain gauges (open dots). The Central Mountain Range $(\mathrm{CMR})$ and Snow Mountain Range (SMR) are labeled. The dotted box $\left(22.5-23.5^{\circ} \mathrm{N}, 120.5-121.0^{\circ} \mathrm{E}\right)$ indicates the area for averaging to compute rainfall histograms in southern CMR. Distributions of (b) observed rainfall (mm) by the gauge network and (c) model-simulated rainfall in CTL over 3 days of 7-9 August 2009. (d)-(f) As in (b), except for individual days from (d) 7 August to (f) 9 August, respectively (as labeled). (g)-(i) As in (d)-(f), except for model-simulated rainfall in CTL on each day, respectively. All accumulation periods are from 0000 to 0000 UTC. 


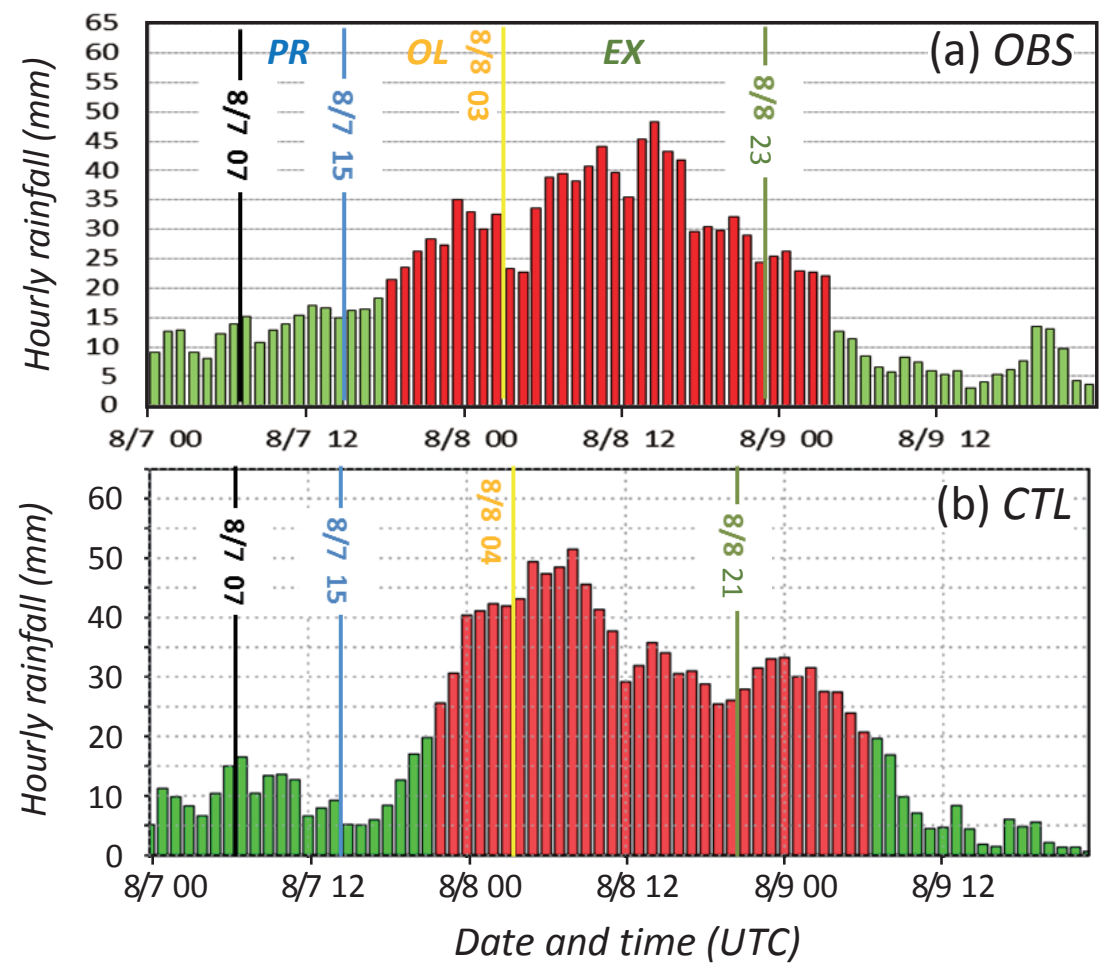

Fig. 9. Hourly rainfall histogram over the southern CMR, averaged inside the box presented in Fig. 8a, from 0000 UTC 7 August to 0000 UTC 10 August 2009, in (a) observations from rain gauges and (b) model simulation in CTL. Red bars indicate rainfall reaching $20 \mathrm{~mm}$ (per hour), and the vertical lines mark the starting/ending times of $\mathrm{PR}, \mathrm{OL}$, and EX phases as labeled, respectively (see text for details).

ated with TY Morakot in the IC. Nonetheless, a weak circulation is still observed at low levels (cf. Figs. $4 \mathrm{f}, 5 \mathrm{f}$ ) due to the monsoon gyre in the background. Below, the sensitivity test results are discussed and compared with that of $\mathrm{C} 0$ (CTL) and among themselves. Also, to facilitate the discussion, $\mathrm{C} 1$ to $\mathrm{C} 5$ are arranged such that their $q^{\prime}$ decreases, especially within $250 \mathrm{~km}$ from the TC center. While a few other tests were also conducted, the results are similar to $\mathrm{C} 1-\mathrm{C} 5$ and thus not presented.

When the PV perturbation of TY Morakot was reduced in the initial field from C1 to C5 (cf. Figs. 4, 5), its track gradually deviated from that of $\mathrm{C}$, mainly before 9 August (Fig. 10). While the deviations were quite small in $\mathrm{C} 1$ and $\mathrm{C} 2$, they became larger from $\mathrm{C} 3$ to $\mathrm{C} 5$, where the changes in $q^{\prime}$ in the inner core were more significant. In $\mathrm{C} 3-\mathrm{C} 5$, the $\mathrm{TC}$ centers moved more to the south and made landfall earlier on 7 August, with increased looping behavior over land. After turning northward, they also exited the island later on 8 August (all after 1200 UTC) from a spot farther north (at a higher latitude), as compared with
C0 (Fig. 10). Thus, with an earlier landfall and later exit, the OL phase was prolonged. This can also be observed in rainfall histograms (Fig. 11), where the OL phase in $\mathrm{C} 0-\mathrm{C} 5$ lasts $13,15,18,27,28$, and $34 \mathrm{~h}$, respectively. Related to this track difference (and a convergence in all tracks during 9 August toward the end of integration), the EX phase was shortened, from $17 \mathrm{~h}$ in $\mathrm{C} 0$ to only $8 \mathrm{~h}$ in $\mathrm{C} 4$ and $7 \mathrm{~h}$ in $\mathrm{C} 5$. Due to the early landfall, the PR phase was also shortened from 8 to $3 \mathrm{~h}$ from $\mathrm{C} 0$ to $\mathrm{C} 5$ (cf. Fig. 11). Thus, when the TC vortex was reduced in size or weakened in intensity, its track changed to produce a prolonged OL phase (and shortened PR and EX phases) in the model, and the reasons will be discussed later.

In the histogram from $\mathrm{C} 0$ (Fig. 11a), the islandwide averaged rain rate was below $10 \mathrm{~mm} \mathrm{~h}^{-1}$ before and during the PR phase and, in fact, decreased to a relative minimum $\left(\sim 4 \mathrm{~mm} \mathrm{~h}^{-1}\right)$ near TC landfall; it then increased through the OL phase and reached a peak of $\sim 18 \mathrm{~mm} \mathrm{~h}^{-1}$ during the EX phase, before decreasing slowly afterward toward and during 9 August. Compared with this evolution, the mean rain 

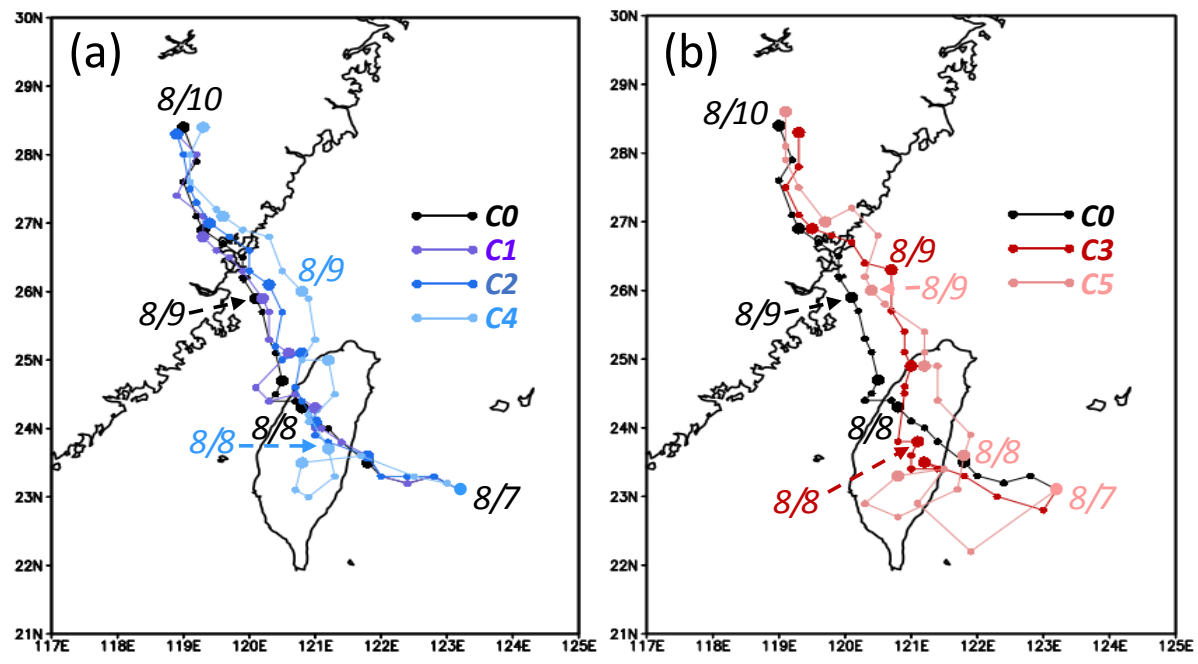

Fig. 10. Comparison of the simulated track of TY Morakot in CTL (C0, black) with those in the sensitivity tests of (a) C1, C2, and C4 and (b) C3 and C5 over the period of 0000 UTC 7-10 August 2009. The TC center positions are given every $3 \mathrm{~h}$ (solid dots) and enlarged every $12 \mathrm{~h}$, and selected ones at 0000 UTC are also labeled.

rates over Taiwan in $\mathrm{C} 1-\mathrm{C} 4$ were actually higher after $t_{0}$, both before and during the PR phase until the first half of the OL phase (Figs. 11a-e). In the second half of the OL phase and the entire EX phase, the mean rain rates in $\mathrm{C} 1-\mathrm{C} 4$ remained similar to slightly less, by about $3-4 \mathrm{~mm} \mathrm{~h}^{-1}$ at most, as compared with $\mathrm{C} 0$ (Figs. 11a-e). After the EX phase, the differences in island-wide rain rates were generally small as the tracks in the tests also converged on 9 August (cf. Fig. $10)$, presumably forced by the same BCs. In C5 where the OL phase was the longest ( $34 \mathrm{~h})$ among all tests (and both PR and EX phases were the shortest), the mean rain rates were higher before, during, and shortly after the PR phase but became the lowest among all cases (including $\mathrm{C} 0$ ) during the second half of the OL phase and the EX phase (after about 1800 UTC 7 August, Fig. 11f). Therefore, while indeed less overall rainfall was received over Taiwan for the OL and EX phases (roughly between 1800 UTC 7 and 0000 UTC 9 August) in $\mathrm{C} 1-\mathrm{C} 5$ as the TC weakened, this was not the case during the earlier period (also Table 3). Thus, the issue appears to be more complicated than one might expect based on intuition.

For the region of the SCMR, the mean rain rate in $\mathrm{C} 0$ reached its peak of over $50 \mathrm{~mm} \mathrm{~h}^{-1}$ near 0800 UTC 8 August, and was nearly the highest during the EX phase among all cases (Figs. 9b, 11g). From $\mathrm{C} 1$ to $\mathrm{C} 5$, while the mean rain rates also tended to be higher before and during the PR phase until the early part of the OL phase compared with $\mathrm{C} 0$, significant decreases were observed during the middle part of their OL phase surrounding 0000 UTC 8 August by up to $20-$ $40 \mathrm{~mm} \mathrm{~h}^{-1}$ in $\mathrm{C} 3-\mathrm{C} 5$ (Figs. 11j-1). Some decreases also continued into the EX phase in $\mathrm{C} 3-\mathrm{C} 5$, which were shortened. The above differences indicate a change in the evolution of rainfall over the SCMR: it started early with more rain received before 1800 UTC 7 August, but during the EX phase on 8 August, when the observed rainfall (and also in CTL/C0) was the most intense, less rain was received if the TC size was significantly reduced or its inner core weakened. On 8 August, the slightly higher rainfall in $\mathrm{C} 3$ over the SCMR compared with $\mathrm{C} 4$ was consistent with its stronger outer circulation beyond $250 \mathrm{~km}$ (Figs. 11j, k, cf. Figs. 2, 4d, e, 5d, e). For the weakest case in $\mathrm{C} 5$, the mean rain rate in SCMR had an evolution very different from $\mathrm{C} 0$ and never exceeded $30 \mathrm{~mm} \mathrm{~h}^{-1}$ during the OL and EX phases (Fig. 111). In C5, however, there still existed an early period of heavy rain, a common feature in all the tests in which the $q^{\prime}$ in the inner core $(\leq 250 \mathrm{~km})$ was weakened and RMW decreased (i.e., C3-C5). Overall, the reduction in rainfall for the OL and EX phases (after 1800 UTC 7 August) in response to the weakening of the TC was more significant over the SCMR (Figs. 11g-1) compared with the entire island (Figs. 11a-f). This implies that as the $q^{\prime}$ of the TC is reduced, the rainfall becomes somewhat less concentrated over the SCMR.

The spatial distributions of the total rainfall over Taiwan, accumulated over different track phases 

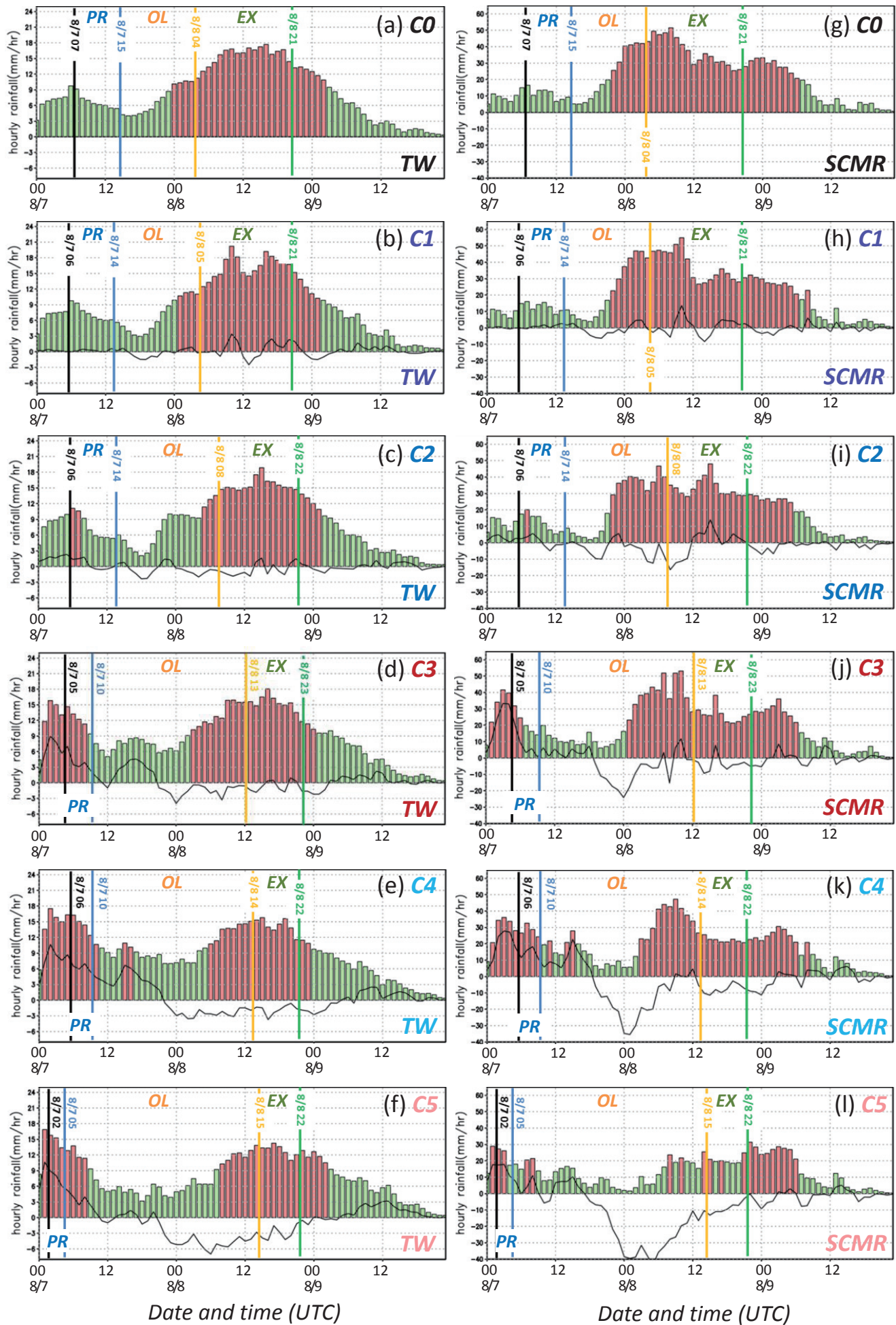

Fig. 11. (a), (g) As in Fig. 9, except for (a) the island of Taiwan (TW) and (g) the southern CMR (SCMR) in CTL (C0). (b)-(f) As in (a) but for the results in (b) $\mathrm{C} 1$ to (f) C5, respectively. (h)-(l) As in (g) but for the results in (h) $\mathrm{C} 1$ to (l) $\mathrm{C} 5$, respectively. The black curves in (b)-(f) and (h)-(l) present the differences from $\mathrm{C} 0$, and the bars for island-wide averages are plotted in red if reaching $10 \mathrm{~mm}$ (left column). 
Table 3. Comparison of duration $(D, \mathrm{~h})$, mean rainfall $(R, \mathrm{~mm})$ over Taiwan and its relative change in percent from $\mathrm{C} 0$ in $( \pm \%$, in parentheses, rounded to closest integer, for $\mathrm{C} 1-\mathrm{C} 5)$, and mean rainrate $\left(R R=R / D, \mathrm{~mm} \mathrm{~h}^{-1}\right)$ at different phases of PR+ (initial time to landfall), OL, EX, post-EX (end of EX to end of integration), and for the total 72-h integration period (0000 UTC 7 to 0000 UTC 10 August 2009) among the experiments of C0-C5.

\begin{tabular}{|c|c|c|c|c|c|c|c|c|c|c|c|c|c|c|}
\hline \multirow{2}{*}{ Exp. } & \multicolumn{3}{|c|}{$\mathrm{PR}+$} & \multicolumn{3}{|c|}{$\mathrm{OL}$} & \multicolumn{3}{|c|}{ EX } & \multicolumn{3}{|c|}{ Post-EX } & \multicolumn{2}{|c|}{ Total } \\
\hline & $D$ & $R$ & $R R$ & $D$ & $R$ & $R R$ & $D$ & $R$ & $R R$ & $D$ & $R$ & $R R$ & $R$ & $R R$ \\
\hline $\mathrm{C} 0$ & 15 & 101.1 & 6.7 & 13 & 91.6 & 7.0 & 17 & 264.5 & 15.6 & 27 & 145.2 & 5.4 & 602.4 & 8.4 \\
\hline $\mathrm{C} 1$ & 14 & $\begin{array}{l}98.9 \\
(-2)\end{array}$ & 7.1 & 15 & $\begin{array}{l}105.0 \\
(+15)\end{array}$ & 7.0 & 16 & $\begin{array}{c}262.1 \\
(-1)\end{array}$ & 16.4 & 27 & $\begin{array}{c}148.6 \\
(+2)\end{array}$ & 5.5 & $\begin{array}{c}614.6 \\
(+2)\end{array}$ & 8.5 \\
\hline $\mathrm{C} 2$ & 14 & $\begin{array}{c}108.8 \\
(+8)\end{array}$ & 7.8 & 18 & $\begin{array}{l}137.7 \\
(+50)\end{array}$ & 7.7 & 14 & $\begin{array}{l}218.7 \\
(-17)\end{array}$ & 15.6 & 26 & $\begin{array}{l}131.3 \\
(-10)\end{array}$ & 5.1 & $\begin{array}{c}596.5 \\
(-1)\end{array}$ & 8.3 \\
\hline $\mathrm{C} 3$ & 10 & $\begin{array}{l}120.9 \\
(+20)\end{array}$ & 12.1 & 27 & $\begin{array}{c}255.0 \\
(+178)\end{array}$ & 9.4 & 10 & $\begin{array}{l}152.1 \\
(-42)\end{array}$ & 15.2 & 25 & $\begin{array}{l}123.9 \\
(-15)\end{array}$ & 5.0 & $\begin{array}{c}651.9 \\
(+8)\end{array}$ & 9.1 \\
\hline C4 & 10 & $\begin{array}{l}142.1 \\
(+41)\end{array}$ & 14.2 & 28 & $\begin{array}{c}281.6 \\
(+207)\end{array}$ & 10.1 & 8 & $\begin{array}{l}114.0 \\
(-57)\end{array}$ & 14.3 & 26 & $\begin{array}{c}135.9 \\
(-6)\end{array}$ & 5.2 & $\begin{array}{l}673.6 \\
(+12)\end{array}$ & 9.4 \\
\hline $\mathrm{C} 5$ & 5 & $\begin{array}{c}69.6 \\
(-31)\end{array}$ & 13.9 & 34 & $\begin{array}{c}266.6 \\
(+191)\end{array}$ & 7.8 & 7 & $\begin{array}{c}90.0 \\
(-66)\end{array}$ & 12.9 & 26 & $\begin{array}{c}154.3 \\
(+6)\end{array}$ & 5.9 & $\begin{array}{c}580.5 \\
(-4)\end{array}$ & 8.1 \\
\hline
\end{tabular}

rather than on each day, in $\mathrm{C} 0-\mathrm{C} 5$ are presented and compared in Fig. 12, whereas the areal-mean values in Taiwan are presented in Table 3. Since the response in rainfall to a TC size reduction (or circulation strength reduction) was similar during the relatively short PR phase and its preceding hours after $t_{0}$, the two periods were combined here and named "PR+". With a comparable length of accumulation among the stages, the heavy rainfall over Taiwan in $\mathrm{C} 0$ generally started from the southernmost part of the CMR in the PR+ phase (15 h, Fig. 12a) and moved slowly northward in the OL phase (13 h, Fig. 12g). Thus, during the PR+ and OL phases, most other regions in Taiwan received relatively little rainfall in $\mathrm{C} 0$ due to the large eye region of TY Morakot (Figs. 12a, g, cf. Figs. 3, 5a). In the EX phase $(17 \mathrm{~h})$, the heavy rainfall extended into the central mountain region and southwesterly plains much more rapidly (Fig. $12 \mathrm{~m}$ ), when the TC center was over the northern Taiwan Strait. The above evolution in $\mathrm{C} 0$ is in agreement with Figs. 6-9, Table 3 , and the previous studies reviewed in Section 1.

While the rainfall differences in $\mathrm{C} 1$ and $\mathrm{C} 2$ from $\mathrm{C} 0$ in the $\mathrm{PR}+$ phase were small in general (Figs. 12b, c), the significantly smaller/weaker TCs in $\mathrm{C} 3-\mathrm{C} 5$ produced considerably more rain over central and southern Taiwan, despite a shorter duration of $10 \mathrm{~h}$ in $\mathrm{C} 3$ and $\mathrm{C} 4$ and just $5 \mathrm{~h}$ in $\mathrm{C} 5$ (Figs. $12 \mathrm{~d}-\mathrm{f}$, Table 3 ). Thus, the dramatic increase in the mean rain rates seen from Figs. 11d-f during the PR+ phase was mainly due to a more widespread rainfall along much of the CMR not present in C0 (cf. Fig. 12a). As noted, as the
TC weakened or reduced in size in the IC, both the eye and the RMW also became smaller (cf. Fig. 5). As a result, the ring of low-level convergence encircling the eye also gradually shrank in size (Figs. 13a-d), thus allowing the associated rainbands, especially the ones south of the TC center, to move over land and produce rainfall (Figs. 12a-e). It can be also seen from Figs. $12 \mathrm{a}$ and $12 \mathrm{~d}-\mathrm{f}$ that most of the rainfall during PR+ was located offshore and just south of Taiwan in $\mathrm{C} 0$, but more rain occurred onshore with less rain farther south in $\mathrm{C} 3-\mathrm{C} 5$. In $\mathrm{C} 5$, the rainfall increased only slightly in central Taiwan and decreased in the SCMR and northeastern Taiwan (compared with $\mathrm{C} 0$ ), as the $\mathrm{PR}+$ lasted only $5 \mathrm{~h}$ (Fig. 12f).

In the OL phase, the rainfall associated with the ring-like low-level convergence zone in $\mathrm{C} 0$ can be clearly seen encircling the eye of the TC and also Taiwan (Fig. 12g), with its southern part crossing the SCMR (and also the offshore area farther south) and consistent with Wang et al. $(2012,2013 b)$ and Chen et al. (2017). At this stage, more rain was also produced over the SCMR in C1 and C2, mainly because of a lengthened OL phase (Figs. 12h, i), as the mean rain rate did not increase much (cf. Figs. 11h, i, Table 4). In $\mathrm{C} 3-\mathrm{C} 5$, significant rainfall increases occurred not only along much of the CMR but also at the northeastern quadrant and over the western/southwestern plains in Taiwan $(>300-400 \mathrm{~mm}$ in many places, Figs. $12 \mathrm{j}-1$ ), as the OL phase lasted $27-34 \mathrm{~h}$ in association with the track change (cf. Fig. 10). The overall size reduction of the ring-like convergence zone in 

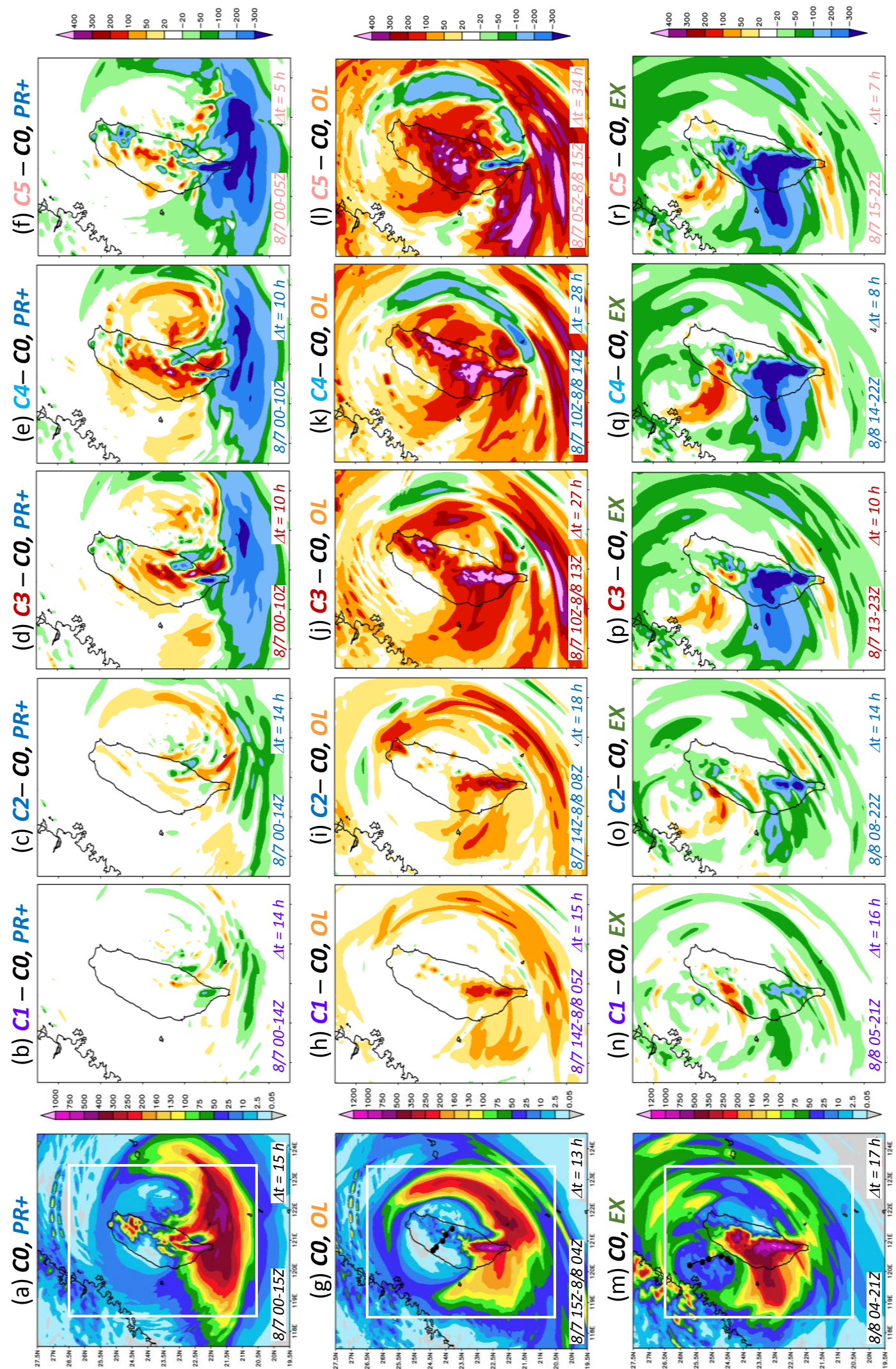

$\Theta \dot{\theta}$

욜

仓ิ

पे

के 흉

골를

ㄹ.

氖起

密

:

I ( )

욤

$\begin{array}{ccc}0 & \\ 0 & 0 \\ 0 & 0 \\ 0 & 0 \\ 0 & 0 \\ 0 & 0 \\ 0\end{array}$

穵希主

:

चै $\vec{\Phi} \cong$

ᄋ 츨 용

$\exists$ 월

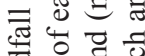

氜 苛

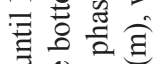

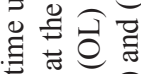

त व

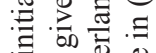

记

בิ

을

त $3 \frac{1}{30}$

ส․ㅠ.

on

夆 $三$

歌

声的总

สีย है

声芯令

ज्ञाँ

寻名焉

퓽

ส

๙

ㄷํ 000

को 

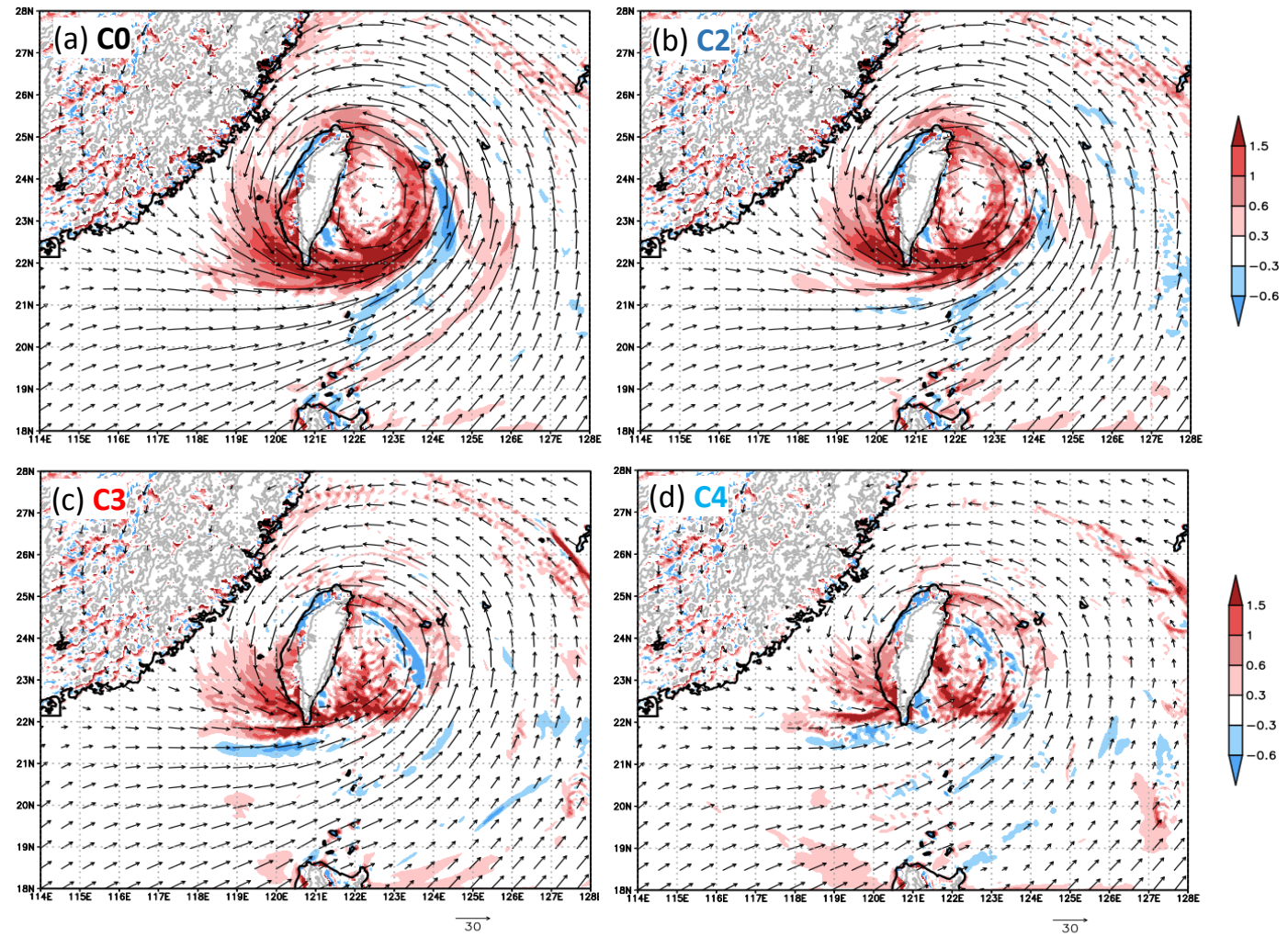

Fig. 13. Horizontal wind vectors $\left(\mathrm{m} \mathrm{s}^{-1}\right.$, reference length at the bottom) and convergence $\left(10^{-4} \mathrm{~s}^{-1}\right.$, color, scale on the right, positive for convergence) at the height of $559 \mathrm{~m}$ (indicated by gray contours), averaged over the PR+ phase (from initial time until landfall), in experiments (a) $\mathrm{C} 0$, (b) $\mathrm{C} 2$, (c) $\mathrm{C} 3$, and (d) $\mathrm{C} 4$, respectively.

the OL phase in $\mathrm{C} 2-\mathrm{C} 5$, as compared with $\mathrm{C} 0$, was evident. Furthermore, additional rainfall over much of central Taiwan, again not present in C0 (cf. Fig. 12g), already appeared (Figs. 12j-1) and was associated with a smaller eye, leading to an overall much larger rain area and thus increased mean rain rates (cf. Table 3 ). Thus, a similar response continued into the PR+ phase. Nonetheless, in the weakest case of $\mathrm{C} 5$, the rainfall increase over much of Taiwan was mostly within 400-500 mm (Fig. 121), which were not great amounts considering that the OL phase in C5 was 21 $\mathrm{h}$ longer than that in $\mathrm{C} 0$. In addition, even with such a lengthy OL phase, the total rainfall in C5 near and just east of the ridge in SCMR (cf. Fig. 8a) still decreased by a few hundred millimeters, corresponding to the lowest rain rate (among all cases) of only $12.2 \mathrm{~mm} \mathrm{~h}^{-1}$ (Table 4).

Finally, in the EX phase, which was the most-rainy period in reality, more widespread and persistent rainfall occurred in $\mathrm{C} 0$ during this lengthy 17 -h period (Fig. $12 \mathrm{~m}$, Table 3). Compared with $\mathrm{C} 0$, the rainfall reduced significantly from $\mathrm{C} 0$ to $\mathrm{C} 5$ as its length shortened from 16 to $7 \mathrm{~h}$ (Figs. 12n-r, Table 3), mainly in the SCMR but also over the southwestern plains. As the TC became smaller and weaker (cf. Fig. 5), not only was the EX phase shortened, but the mean rain rate in the SCMR was also reduced, from $37.5 \mathrm{~mm} \mathrm{~h}^{-1}$ in $\mathrm{C} 0$ to only $20.3 \mathrm{~mm} \mathrm{~h}^{-1}$ in C5 (Table 4), consistent with the earlier discussion related to Fig. 11. Nevertheless, there still existed an area of increased rainfall (as compared with $\mathrm{C} 0$ ) close to the TC center (near northwestern Taiwan) in $\mathrm{C} 1-\mathrm{C} 5$ in the EX phase (Figs. $12 n-r)$, in spite of its shortened period length. This is a common feature in the two preceding phases (PR+ and OL) and is also linked to the smaller eye size of the TCs when they are weakened.

After the EX phase and on 9 August 2009, the TC tracks in all the tests gradually converged toward the best track (Figs. 6a, 10), and their rainfall scenarios, including $\mathrm{C} 5$, were all similar with only minor differences as the TC gradually moved away from Taiwan (Fig. 11, Table 3, spatial distributions not shown). 
Table 4. As in Table 3, except for the comparison of $D(\mathrm{~h}), R(\mathrm{~mm})$ and its relative change from $\mathrm{C} 0$ in $( \pm \%$, in parentheses), and $R R\left(\mathrm{~mm} \mathrm{~h}^{-1}\right)$ averaged over the SCMR at the phases of OL, EX, and the combined period of the two $(\mathrm{OL}+\mathrm{EX})$ among the experiments.

\begin{tabular}{|c|c|c|c|c|c|c|c|c|c|}
\hline \multirow{2}{*}{ Exp. } & \multicolumn{3}{|c|}{$\mathrm{OL}$} & \multicolumn{3}{|c|}{ EX } & \multicolumn{3}{|c|}{$\mathrm{OL}+\mathrm{EX}$} \\
\hline & $D$ & $R$ & $R R$ & $D$ & $R$ & $R R$ & $D$ & $R$ & $R R$ \\
\hline $\mathrm{CO}$ & 13 & 296.0 & 22.8 & 17 & 637.4 & 37.5 & 30 & 933.4 & 31.1 \\
\hline $\mathrm{C} 1$ & 15 & $335.3(+13)$ & 22.4 & 16 & $607.2(-5)$ & 38.0 & 31 & $942.5(+1)$ & 30.4 \\
\hline $\mathrm{C} 2$ & 18 & $428.8(+45)$ & 23.8 & 14 & $471.1(-26)$ & 33.7 & 32 & $899.9(-4)$ & 28.1 \\
\hline $\mathrm{C} 3$ & 27 & $643.4(+117)$ & 23.8 & 10 & $264.9(-58)$ & 26.5 & 37 & $908.3(-3)$ & 24.5 \\
\hline $\mathrm{C} 4$ & 28 & $614.7(+108)$ & 22.0 & 8 & $178.2(-72)$ & 22.3 & 36 & $792.9(-15)$ & 22.0 \\
\hline $\mathrm{C} 5$ & 34 & $415.7(+40)$ & 12.2 & 7 & $142.0(-78)$ & 20.3 & 41 & $557.7(-40)$ & 13.6 \\
\hline
\end{tabular}

This indifference among the cases toward the end of the test was anticipated, since the $q^{\prime}$ modification was only in the initial field and on the TC vortex.

\section{Discussion}

While differences among the sensitivity test results also existed during the OL and EX phases, they were evident during the $\mathrm{PR}+$ phase, i.e., during the early stages of the integration, as shown in Section 4. In particular, in tests where the $q^{\prime}$ in the inner core was reduced (in $\mathrm{C} 3-\mathrm{C} 5$ ), rain began over Taiwan (including its mountainous areas) soon after $t_{0}$, thus causing higher areal-mean rain rates (Figs. 11d-f, 12d-f, Table 3). This increase in rainfall was accompanied by a reduction in the size of the eye (cf. Fig. 13), an early TC landfall, and a shortening in PR (and PR+) phase and a prolonged OL phase (Figs. 10, 11, Table $3)$. Also, the more the inner-core $q^{\prime}$ was reduced, the longer the OL phase, which lasted from $13 \mathrm{~h}$ in $\mathrm{C} 0$ to $34 \mathrm{~h}$ in $\mathrm{C} 5$. This significant track change and the associated rainfall scenario in Taiwan are linked to a rapid vortex spin-up, which is further discussed below.

\subsection{Vortex spin-up and changes in track}

The time series of surface maximum wind speed and minimum SLP in C0-C5 are compared in Fig. 14, whereas the run $\mathrm{C} 3 \mathrm{~A}$ will be discussed later in Section 5.3. While $\mathrm{TC}$ intensification also occurred in $\mathrm{C} 0$ during the first several hours as noted earlier, as can be seen here, in all tests where the initial TC intensity was reduced, a more rapid spin-up occurred soon after $t_{0}$ with a drop in central SLP. As a result, the vortex was typically brought back to an intensity comparable with that in $\mathrm{C} 0$ within $12 \mathrm{~h}$, sometimes even stronger in terms of wind speed (Figs. 14a, c). This existed even in cases where the initial deficit in maximum wind speed exceeded $15 \mathrm{~m} \mathrm{~s}^{-1}$, such as $\mathrm{C} 3$ and $\mathrm{C} 4$, with a longer period of intensification and often at a higher rate. The only exception was the vortex in C5 (Figs. 14c, d), whose initial intensity was below 7 $\mathrm{m} \mathrm{s}^{-1}$. Consequently, it was at least $10 \mathrm{~m} \mathrm{~s}^{-1}$ weaker than the $\mathrm{TC}$ in $\mathrm{C} 0$ throughout 7 August and only reached a peak intensity of $32 \mathrm{~m} \mathrm{~s}^{-1}$ near 0900 UTC 8 August (while the two became close afterward). In other words, the initial vortex in C5 is too weak for its strength to recover in time, perhaps similar to the one using BDA by Huang et al. (2011) as reviewed in Section 1 (but with a different $t_{0}$ ). However, the vortex in C5 here does make landfall, which is a situation more ideal for our study. Based on previous results (Wang et al. 2012, 2013b) and other additional tests (not shown), such a track difference is likely mainly caused by different TC structures and interaction with the environment. Toward the end of the simulation, on the other hand, all TCs in $\mathrm{C} 0-\mathrm{C} 5$ became close in intensity (Fig. 14), likely also contributing to their similar tracks on 9 August noted earlier (cf. Fig. 10).

The vortex spin-up at the early stage implied inward flow at low levels near the inner core and a contraction of the eye (e.g., Hack and Schubert 1986; Holton 2004, Section 9.7.2; Smith et al. 2009; Smith and Montgomery 2016), which can be examined in Fig. 15 for $\mathrm{C} 2-\mathrm{C} 5$. Even though the near-surface cyclonic flow in the $\mathrm{PR}+$ phase, as compared to $\mathrm{C} 0$, was reduced at $r \geq 150 \mathrm{~km}$ and some quite significantly (blue region, Fig. 15, left column), there existed a ring of increased wind speed at smaller radii of about $100-150 \mathrm{~km}$ (red region). Thus, the spin-up and contraction of the eyewall was confirmed, and the smaller eye in $\mathrm{C} 2-\mathrm{C} 5$ persisted into the OL and EX phases (Fig. 15, middle and right columns). The smaller eye (and RMW, cf. Fig. 5) was also consistent with the reduced radius of the circular ring-like rainfall area (and the associated low-level convergence zone) seen from Fig. 12. Here, it should be noted that in Fig. 5, upper-level outflow appears to exist at about 12-16 

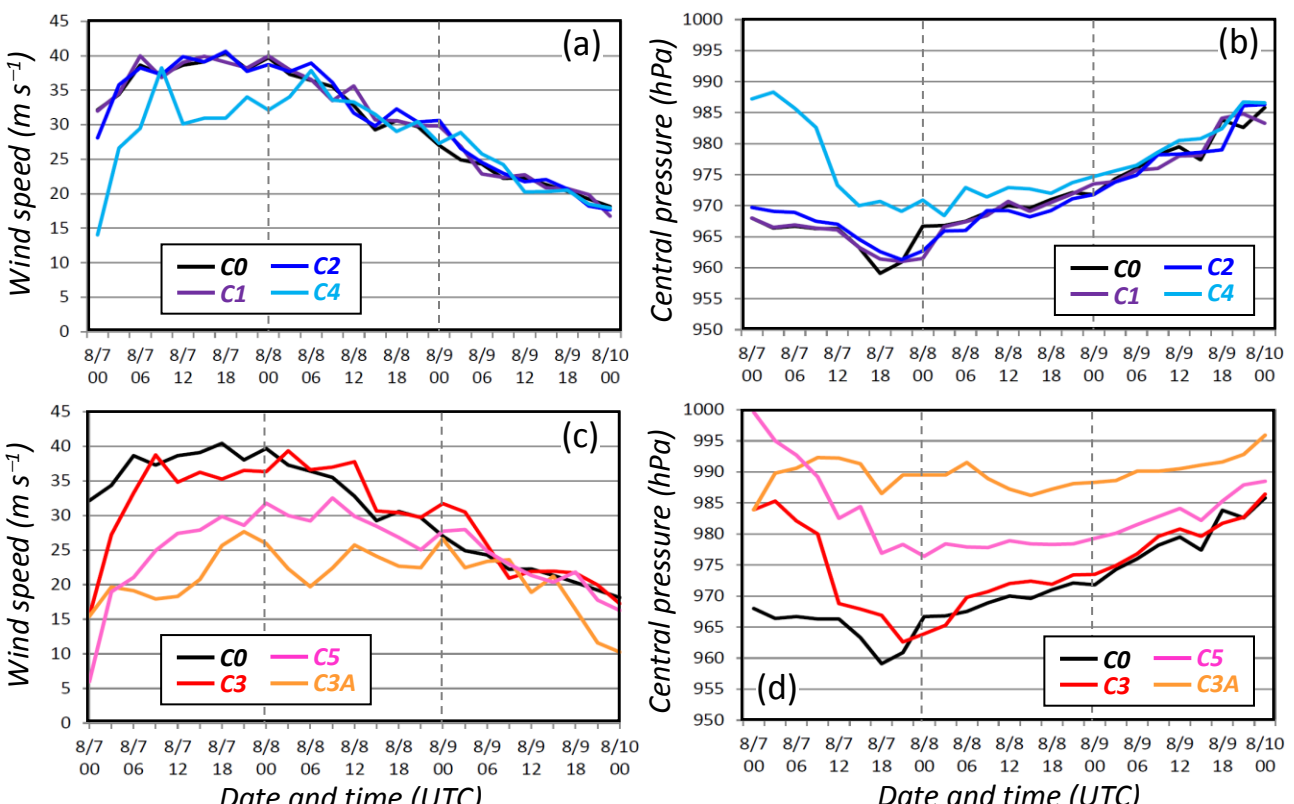

Fig. 14. Time series of (a) surface maximum wind speed $\left(\mathrm{m} \mathrm{s}^{-1}\right)$ near the TC center and (b) minimum sea-level pressure $(\mathrm{hPa})$ during the simulation period (0000 UTC 7-10 August 2009) in experiments C0, C1, C2, and C4. (c), (d) As in (a), (b), except for experiments C0, C3, C3A, and C5, respectively.

$\mathrm{km}$ at $t_{0}$, but it is mainly caused by a northeasterly flow aloft (in the mean/background field) at the southern to southwestern quadrants of the TC (e.g., Chien and Kuo 2011; Wang et al. 2012). Even when the divergent flow $\left(\mathbf{v}_{\chi}, \mathbf{v}_{\chi}=-\nabla \chi\right.$, where $\chi$ is velocity potential) was removed and the vortex became balanced (e.g., Chen et al. 2008), the evolution of the model TC (including track and intensity) remained nearly the same (figure omitted). Thus, this northerly flow and apparent outflow aloft at $t_{0}$ did not cause the vortex spin-up. In addition, the wavy patterns east of the TC (near $126^{\circ} \mathrm{E}$ ) in Figs. 15f, 15i, and 151 were due to different rainband locations in $\mathrm{C} 0$ versus the sensitivity test there, i.e., linked to track differences in the EX phase (cf. Fig. 10).

\subsection{Interactions of TY Morakot with southwesterly flow}

Since both an imbalance and asymmetry of the TC flow were retained in our methods to modify the IC, there remained a strong interaction between TY Morakot and the southwesterly flow even in the sensitivity tests. Immediately after $t_{0}$, convection developed in a moisture-rich TC environment to produce rainfall, mainly along the low-level convergence zone to the south of the TC center and over Taiwan (cf. Figs. 12d-f). In Fig. 16a, an example of $\mathrm{C} 3$ at $2 \mathrm{~h}$ after $t_{0}$ is shown, and the latent heating from this convection presumably drives the vortex spin-up. While the southwesterly flow and its convergence with the TC circulation have been studied quite extensively in earlier works (Section 1; e.g., Chien and Kuo 2011; Wang et al. 2012, 2015; Chen et al. 2017), the convergence zone and rainfall also move onshore when spin-up and contraction take place in cases with a reduced $q^{\prime}$ in the inner core (cf. Fig. 16b). This shift means that the southwesterly flow can now bring in the moisture and impinge on Taiwan's topography directly only a few hours into the integration (e.g., Figs. 12d-f, 13c, d, 16b), a scenario that does not happen in $\mathrm{C} 0$ with a stronger outer TC circulation and the convergence zone still mostly offshore (cf. Figs. 7g, 12a, 13a). Thus, in TY Morakot (2009), not only were the previously identified factors of convection (latent heating), southwesterly flow (moisture supply), TC motion, and the topography of Taiwan working together in synergy (e.g., Wang et al. 2013a; Hsu et al. 2013; Chen et al. 2017), the vortex structure apparently was also involved and played a role in this complex interaction in determining the rainfall evolution in Taiwan. 

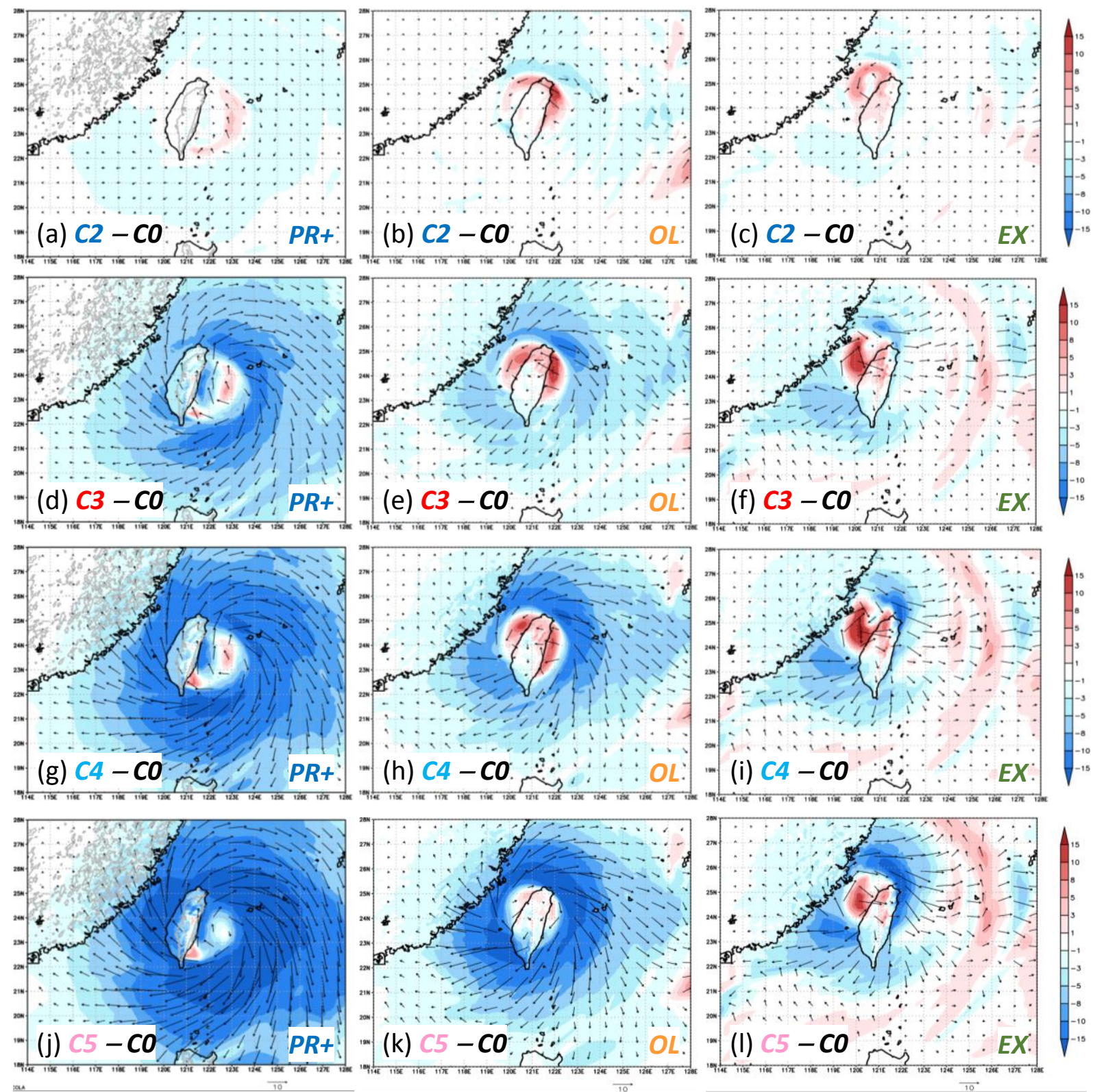

Fig. 15. Differences in surface wind vectors $\left(\mathrm{m} \mathrm{s}^{-1}\right.$, at 10-m height, reference length at the bottom) of $\mathrm{C} 2$ from $\mathrm{C} 0$ (C2 minus C0) averaged over the phase of (a) PR+ (initial time until landfall), (b) OL, and (c) EX, respectively. Color shows wind speed differences (scale on the right). (d)-(f), (g)-(i), (j)-(l) As in (a)-(c), except for (d)-(f) $\mathrm{C} 3$ minus $\mathrm{C} 0$, (g)-(i) $\mathrm{C} 4$ minus $\mathrm{C} 0$, and (j)-(1) C5 minus $\mathrm{C} 0$ for the three phases, respectively.

\subsection{Additional sensitivity test on impacts of moisture}

The early spin-up during the $\mathrm{PR}+$ phase in $\mathrm{C} 3-\mathrm{C} 5$ was associated with active convection at smaller radii, mostly inside $r=150-200 \mathrm{~km}$ (cf. Figs. 12d-f, Table 3 ), in a moisture-rich and highly unstable environment (e.g., Chien and Kuo 2011; Huang et al. 2011), and the associated latent heat release was speculated to be the main driver for this process (and the eyewall contraction). To confirm this hypothesis, an additional experiment was conducted. Named C3A, the test used the same IC as in $\mathrm{C} 3$ with an identical setup, but the moisture content inside $r=750 \mathrm{~km}$ was also cut in 

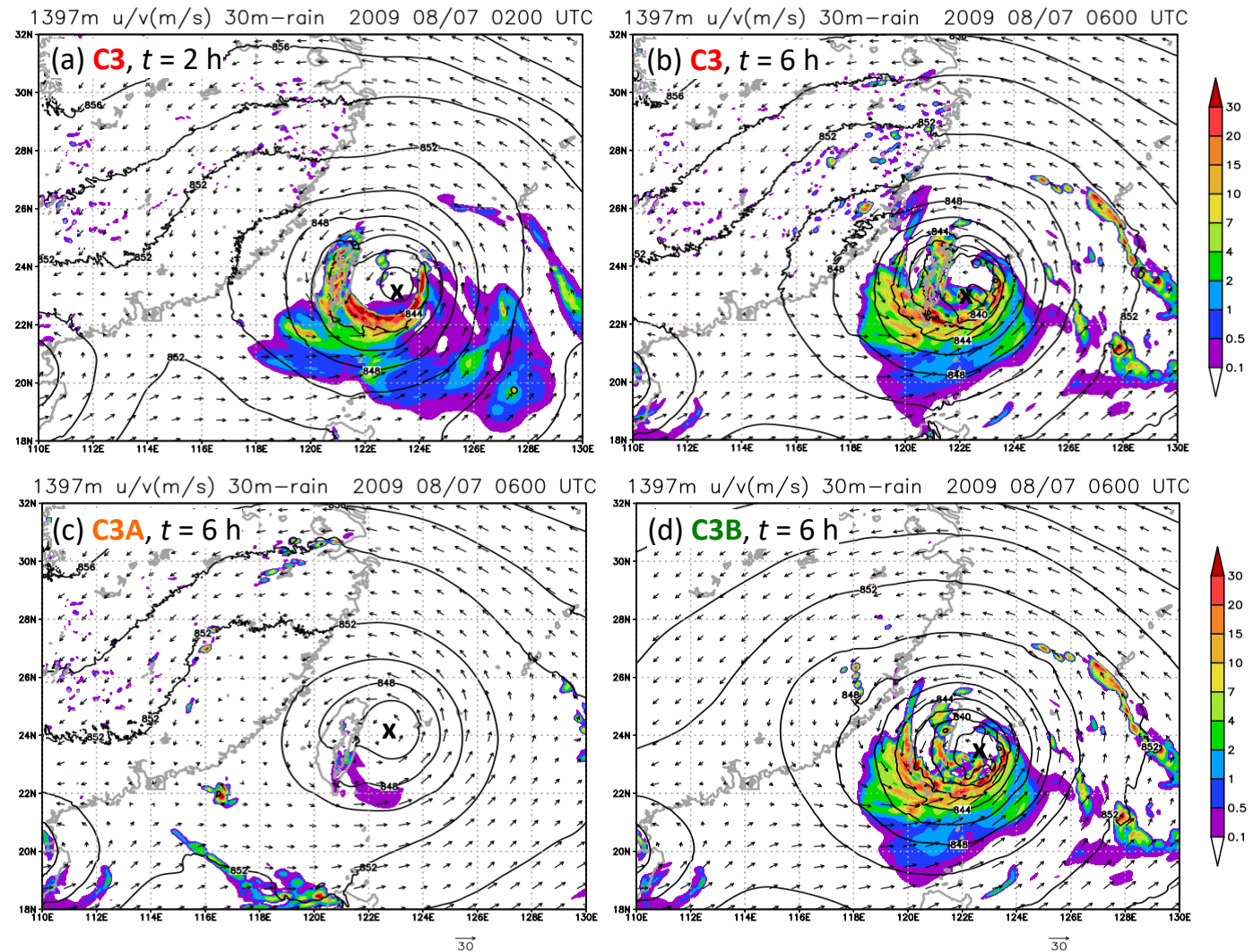

Fig. 16. Horizontal wind vectors ( $\mathrm{m} \mathrm{s}^{-1}$, reference length at the bottom) and pressure (hPa, isobars every $\left.2 \mathrm{hPa}\right)$ at the height of $1397 \mathrm{~m}$ (depicted by gray contours) and 30-min rainfall (mm, color) at (a) 0200 UTC 7 August ( $\left.t_{+2}\right)$ in C3 and 0600 UTC 7 August $\left(t_{+6}\right)$ in (b) C3, (c) C3A, and (d) C3B, respectively. The TC centers are marked by an " $x$ ".

half (in addition to the change in $q^{\prime}$, cf. Fig. 2b). After the integration started in this test, the TC neither spun up (Fig. 14b) nor was drawn toward Taiwan (Figs. $16 \mathrm{c}, 17)$. Instead, it moved toward the northwest during the first $12 \mathrm{~h}$, then made landfall and moved across northern Taiwan before turning northward on 8 August. Thus, the early spin-up and the associated track changes were confirmed to be caused by the inner-core convection during the $\mathrm{PR}+$ phase.

The lengths of the PR, OL, and EX phases in C3A were 5,8 , and 30 h, respectively (Figs. 17, 18), significantly different from those in $\mathrm{C} 3$ because of the track changes. Nevertheless, the rainfall in the histogram was already much reduced, especially during the entire EX phase (after 1800-2100 UTC 7 August) both for the whole of Taiwan and the SCMR (Figs. $18 \mathrm{a}, \mathrm{b}$, cf. Figs. $11 \mathrm{a}, \mathrm{g}$ ), since the vortex in C3A was even weaker than that in C5 (cf. Figs. 11f, 1, 14c, d). Nevertheless, there still existed a period of $6-7 \mathrm{~h}$ near $\mathrm{TC}$ landfall when the mean rain rate in $\mathrm{C} 3 \mathrm{~A}$ exceeded,

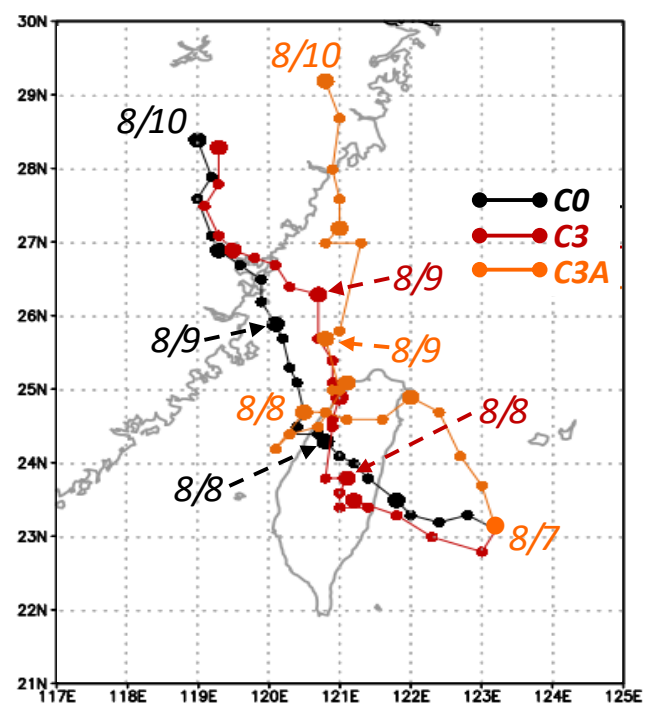

Fig. 17. As in Fig. 10b, except for the comparison among $\mathrm{TC}$ tracks in $\mathrm{C} 0, \mathrm{C} 3$, and $\mathrm{C} 3 \mathrm{~A}$. 

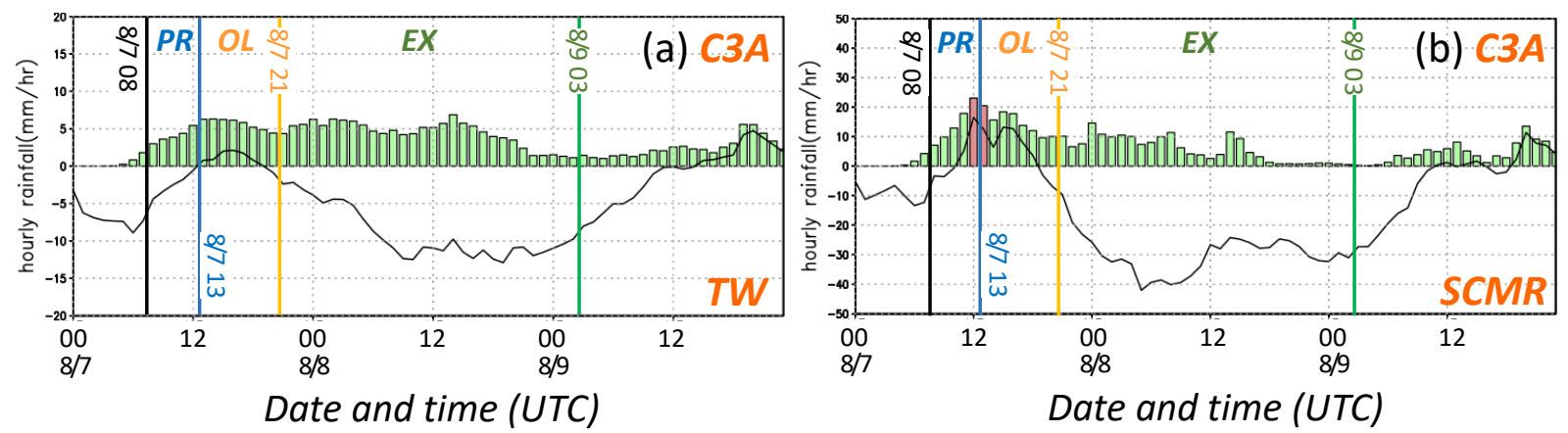

Fig. 18. As in Figs. 11d and 11j, except for the region of (a) TW and (b) SCMR from the results in C3A, respectively. The black curves show the differences from $\mathrm{C} 0$.

or was comparable with, that in $\mathrm{C} 0$, apparently as the abundant moisture initially outside $r=750 \mathrm{~km}$ reached Taiwan.

\subsection{Role of the topography of Taiwan}

In $\mathrm{C} 3-\mathrm{C} 5$, the inner-core convection that is part of the transverse circulation during the $\mathrm{PR}+$ phase produced rainfall in two major areas: one was along the ring of convergence (mainly to the south and reduced in size) and the other was over the mountain regions in Taiwan (cf. Figs. 12d-f, 16b, Table 3; note that the PR+ phase in C5 lasted only $5 \mathrm{~h}$ ). The effect of the topography was further tested in the experiment C3B that had a setup identical to $\mathrm{C} 3$, except that the terrain of Taiwan was reduced to $10 \mathrm{~m}$. In this test, the spin-up occurred as in C3, but the landfall was not as early (Figs. 16b, d). Therefore, the steep topography of Taiwan was not only a key factor in increasing rainfall from TY Morakot (e.g., Ge et al. 2010; Fang et al. 2011; Yu and Cheng 2013) as in many other cases even beyond TCs (e.g., Chang et al. 1993; Wu et al. 2002; Wang et al. 2005), but was also believed to affect the TC track. Using idealized experiments, Hsu et al. (2013) demonstrated that TCs can be drawn toward Taiwan by latent heating phase-locked with the terrain, whereas asymmetric latent heating to the rear side acted to slow down the departure of TY Morakot (also Wang et al. 2012; Chen et al. 2017). In the case of TY Fanapi (2010) that also slowed down upon exit, for example, the rainfall asymmetry was caused by the terrain of Taiwan (Wang et al. 2013a). Since the PV of the TC was reduced in our tests, from a kinematic viewpoint, the same PV tendency (or generation rate) surrounding the center can exert a more significant impact; thus, the weaker the vortex, the larger the response in track changes (e.g., C5, cf. Fig. 10), also consistent with the recent study by Hsu et al. (2018).

\section{Conclusion and summary}

In this study, the impacts of TY Morakot's (2009) size and structure on rainfall in Taiwan were investigated using nonlinear-balanced piecewise PV inversion (Davis and Emanuel 1991; Davis 1992a, b). Using the method described in Sections $2 b$ and 2c, the PV perturbation $q^{\prime}$ associated with TY Morakot, inside a cylindrical volume with $r \leq 750 \mathrm{~km}$ and below 100 $\mathrm{hPa}$, in the initial field was modified according to prescribed functions to reduce its size and circulation strength while retaining an unbalanced component in the mass/flow fields. With an initial time $t_{0}$ at 0000 UTC 7 August 2009, or $15 \mathrm{~h}$ before the observed landfall of the TC center in Taiwan, three sets of sensitivity tests were performed and compared with the control experiment (CTL or $\mathrm{C} 0$ ), and the results from $\mathrm{C} 1$ to $\mathrm{C} 5$, corresponding to a progressively weaker $q^{\prime}$, were presented.

The CTL experiment reproduced the event of TY Morakot (2009) both realistically and faithfully and was validated against the observations (Section 3). The sensitivity tests were then compared with the results of $\mathrm{C} 0$ and among themselves (summarized in Tables 3,4), and the overall findings can be given as below:

1. When the TC vortex is reduced in size and strength, especially in cases where $q^{\prime}$ in the inner core $(\leq$ $250 \mathrm{~km}$ ) is weakened more significantly, it makes landfall earlier, stays over land longer, and then exits the land later, causing an increase in rainfall over Taiwan during about the first $18 \mathrm{~h}$ and then a decrease in rainfall afterward, during the later landfall and exit periods. As a result, the entirety of Taiwan receives at least a comparable overall 
amount or even more rain in all the tests (up to $+12 \%)$, even in C5 (-4\%) where the initial TC $q^{\prime}$ is completely removed (Table 3 ). Thus, a weaker TC does not necessarily lead to less total rainfall over Taiwan from this event.

2. The early landfall and prolonged landfall period in the tests are caused by active convection and latent heating in the inner core at smaller radii (near and over Taiwan) under the abundant moisture supply by the low-level southwesterly flow, with a spin-up and contraction of the TC vortex. This result indicates that the southwesterly flow, with its moisture supply and the steep terrain of Taiwan, is a factor of higher overall importance than the vortex structure of the TC to the extreme rainfall in Taiwan in the event of TY Morakot (2009).

3. With a weaker TC circulation, however, the total rainfall in the SCMR during the landfall and exit period (roughly from 1800 UTC 7 to 1800 UTC 8 August), the latter of which is the most-rainy period in reality (with an areal-mean accumulation of 637 $\mathrm{mm}$ in $\mathrm{C} 0$ ), tends to decrease. This decrease is up to $40 \%$ in $\mathrm{C} 5$ (and $15 \%$ in $\mathrm{C} 4$ ), despite the longer combined length for the period (Table 4). Thus, the rainfall patterns are considerably different, and the TC vortex structure plays a more important role in the SCMR (as compared with other regions) on 8 August during the exit phase.

The above conclusion that the southwesterly flow plays a more important overall role than the vortex structure of TY Morakot (2009) to the total rainfall in Taiwan is consistent with the study by Chen et al. (2017), who found a high correlation (with a correlation coefficient as high as 0.93 ) between the rainfall in Taiwan and the product of low-level southwesterly moisture flux upstream and the period duration, for the EX phase of all 17 west-bound TCs that made landfall at the middle portion of Taiwan (as TY Morakot) in June-August, 1960-2016 (their Fig. 2b). For TY Morakot, Jou et al. (2010) also found that the rain rates over the SCMR during the event were well correlated to the strength of low-level southwesterly flow upstream, suggesting the importance of forced uplift by the topography under such conditions (also Lin et al. 2001; Huang and Lin 2014). Indeed, in our sensitivity tests, the mean total accumulated rainfall in Taiwan does not exhibit a significant change (cf. Table 3 ), even in $\mathrm{C} 5$, unless the moisture is reduced in the IC in C3A (cf. Fig. 17).

With a smaller TC and weaker circulation, however, less total rainfall occurs after landfall (OL and EX) in the region of SCMR (Table 4), which received the highest amount in the observation, as summarized above in point 3 . This result is also consistent with the study by $\mathrm{Wu}$ et al. (2011). Therefore, with lower rain rates on 8 August (Fig. 11, right column), the ShiaoLin burying and great loss in lives might not have occurred if TY Morakot was a smaller storm with weaker circulation.

\section{Acknowledgments}

Helpful comments from the anonymous reviewers are highly appreciated. The CWB is acknowledged for providing the observational data and the radar plots in Taiwan, and the help from Dr. Mark I.-M. Wang (National Taiwan University, Taiwan) and Mr. K.-H. Ho (Meteorological and Geophysical Bureau, Macau, China) on PV inversion is also appreciated. This study is jointly supported by the Ministry of Science and Technology (MOST) of Taiwan under Grants MOST105-2111-M-003-003-MY3 and MOST108-2111-M003-005-MY2.

\section{References}

Chang, C.-P., T.-C. Yeh, and J.-M. Chen, 1993: Effects of terrain on the surface structure of typhoons over Taiwan. Mon. Wea. Rev., 121, 734-752.

Chang, C.-P., S. C. Hou, H. C. Kuo, and G. T. J. Chen, 1998: The development of an intense East Asian summer monsoon disturbance with strong vertical coupling. Mon. Wea. Rev., 126, 2692-2712.

Chang, C.-P., Y.-T. Yang, and H. C. Kuo, 2013: Large increasing trend of tropical cyclone rainfall in Taiwan and the roles of terrain. J. Climate, 26, 4138-4147.

Chanson, H., 2010: The impact of Typhoon Morakot on the southern Taiwan coast. Shore Beach, 78, 33-38.

Charney, J. G., 1955: The use of the primitive equations of motion in numerical prediction. Tellus, 7, 22-26.

Chen, G. T.-J., C.-C. Wang, and S. C.-S. Liu, 2003: Potential vorticity diagnostics of a Mei-Yu front case. Mon. Wea. Rev., 131, 2680-2696.

Chen, G. T.-J., C.-C. Wang, and L.-F. Lin, 2006: A diagnostic study of a retreating Mei-yu front and the accompanying low-level jet formation and intensification. Mon. Wea. Rev., 134, 874-896.

Chen, G. T.-J., C.-C. Wang, and S.-W. Chang, 2008: A diagnostic case study of Mei-yu frontogenesis and development of wavelike frontal disturbances in the subtropical environment. Mon. Wea. Rev., 136, 41-61.

Chen, Y.-H., H.-C. Kuo, C.-C. Wang, and Y.-T. Yang, 2017: Influence of southwest monsoon flow and typhoon track on Taiwan rainfall during the exit phase: Modeling study of Typhoon Morakot (2009). Quart. J. Roy. Meteor. Soc., 143, 3014-3024.

Cheung, K. K. W., L.-R. Huang, and C.-S. Lee, 2008: Characteristics of rainfall during tropical cyclone periods 
in Taiwan. Nat. Hazards Earth Syst. Sci., 8, 14631474.

Chien, F.-C., and H.-C. Kuo, 2011: On the extreme rainfall of Typhoon Morakot (2009). J. Geophys. Res., 116, D05104, doi:10.1029/2010JD015092.

Cotton, W. R., G. J. Tripoli, R. M. Rauber, and E. A. Mulvihill, 1986: Numerical simulation of the effects of varying ice crystal nucleation rates and aggregation processes on orographic snowfall. J. Climate Appl. Meteor, 25, 1658-1680.

Davis, C. A., 1992a: Piecewise potential vorticity inversion. J. Atmos. Sci., 49, 1397-1411.

Davis, C. A., 1992b: A potential-vorticity diagnosis of the importance of initial structure and condensational heating in observed extratropical cyclogenesis. Mon. Wea. Rev., 120, 2409-2428.

Davis, C. A., and K. A. Emanuel, 1991: Potential vorticity diagnostics of cyclogenesis. Mon. Wea. Rev., 119, 1929-1953.

Davis, C. A., E. D. Grell, and M. A. Shapiro, 1996: The balanced dynamical nature of a rapidly intensifying oceanic cyclone. Mon. Wea. Rev., 124, 3-26.

Deardorff, J. W., 1980: Stratocumulus-capped mixed layers derived from a three-dimensional model. Bound.Layer Meteor., 18, 495-527.

Ertel, H., 1942: Ein neuer hydrodynamischer wirblsatz. Meteor. Z., 59, 271-281.

Fang, X., Y.-H. Kuo, and A. Wang, 2011: The impact of Taiwan topography on the predictability of Typhoon Morakot's record-breaking rainfall: A high-resolution ensemble simulation. Wea. Forecasting, 26, 613-633.

Ge, X., T. Li, S. Zhang, and M. S. Peng, 2010: What causes the extremely heavy rainfall in Taiwan during Typhoon Morakot (2009)? Atmos. Sci. Lett., 11, 46-50.

Hack, J. J., and W. H. Schubert, 1986: Nonlinear response of atmospheric vortices to heating by organized cumulus convection. J. Atmos. Sci., 43, 1559-1573.

Hendricks, E. A., J. R. Moskaitis, Y. Jin, R. M. Hodur, J. D. Doyle, and M. S. Peng, 2011: Prediction and diagnosis of Typhoon Morakot (2009) using the Naval Research Laboratory's mesoscale tropical cyclone model. Terr. Atmos. Oceanic Sci., 22, 579-594.

Hendricks, E. A., Y. Jin, J. R. Moskaitis, J. D. Doyle, M. S. Peng, C.-C. Wu, and H.-C. Kuo, 2016: Numerical simulations of Typhoon Morakot (2009) using a multiply nested tropical cyclone prediction model. Wea. Forecasting, 31, 627-645.

Holton, J. R., 2004: An Introduction to Dynamic Meteorology. 4th Edition. Academic Press, London, 535 pp.

Hong, C.-C., M.-Y. Lee, H.-H. Hsu, and J.-L. Kuo, 2010: Role of submonthly disturbance and 40-50 day ISO on the extreme rainfall event associated with Typhoon Morakot (2009) in southern Taiwan. Geophys. Res. Lett., 37, L08805, doi:10.1029/2010GL042761.

Hoskins, B. J., M. E. McIntyre, and A. W. Robertson, 1985: On the use and significance of isentropic potential vorticity maps. Quart. J. Roy. Meteor. Soc., 111, 877946.

Hsu, H.-H., H.-C. Kuo, J.-D. Jou, T.-C. Chen, P.-H. Lin, T.-C. Yeh, and C.-C. Wu, 2010: Scientific report on Typhoon Morakot (2009). National Science Council, Taipei, Taiwan, 192 pp (in Chinese).

Hsu, L.-H., H.-C. Kuo, and R. G. Fovell, 2013: On the geographic asymmetry of typhoon translation speed across the mountainous island of Taiwan. J. Atmos. Sci., 70, 1006-1022.

Hsu, L.-H., S.-H. Su, R. G. Fovell, and H.-C. Kuo, 2018: On typhoon track deflections near the east coast of Taiwan. Mon. Wea. Rev., 146, 1495-1510.

Huang, C.-Y., C.-S. Wong, and T.-C. Yeh, 2011: Extreme rainfall mechanisms exhibited by Typhoon Morakot (2009). Terr. Atmos. Oceanic Sci., 22, 613-632.

Huang, C.-Y., Y. Zhang, W. C. Skamarock, and L.-H. Hsu, 2017: Influences of large-scale flow variations on the track evolution of Typhoons Morakot (2009) and Megi (2010): Simulations with a global variableresolution model. Mon. Wea. Rev., 145, 1691-1716.

Huang, H.-L., M.-J. Yang, and C.-H. Sui, 2014: Water budget and precipitation efficiency of Typhoon Morakot (2009). J. Atmos. Sci., 71, 112-129.

Huang, Y.-C., and Y.-L. Lin, 2014: A study on the structure and precipitation of Morakot (2009) induced by the Central Mountain Range of Taiwan. Meteor. Atmos. Phys., 123, 115-141.

Ikawa, M., and K. Saito, 1991: Description of a nonhydrostatic model developed at the Forecast Research Department of the MRI. Technical reports of the Meteorological Research Institute, No 28, Japan, 238 pp.

Jou, B. J.-D., Y.-C. Yu, L. Feng, Y.-M. Chen, C.-S. Lee, and M.-D. Cheng, 2010: Synoptic environment and rainfall characteristics of Typhoon Morakot (0908). Atmos. Sci., 38, 21-38 (in Chinese).

Kondo, J., 1976: Heat balance of the China Sea during the air mass transformation experiment. J. Meteor. Soc. Japan, 54, 382-398.

Lee, C.-S., C.-C. Wu, T.-C. C. Wang, and R. L. Elsberry, 2011: Advances in understanding the "perfect monsoon-influenced typhoon": Summary from international conference on Typhoon Morakot (2009). AsiaPac. J. Atmos. Sci., 47, 213-222.

Liang, J., L. Wu, X. Ge, and C.-C. Wu, 2011: Monsoonal influence on Typhoon Morakot (2009). Part II: Numerical study. J. Atmos. Sci., 68, 2222-2235.

Lin, Y.-L., R. D. Farley, and H. D. Orville, 1983: Bulk parameterization of the snow field in a cloud model. $J$. Climate Appl. Meteor, 22, 1065-1092.

Lin, Y.-L., S. Chiao, T.-A. Wang, M. L. Kaplan, and R. P. Weglarz, 2001: Some common ingredients for heavy orographic rainfall. Wea. Forecasting, 16, 633-660.

Louis, J. F., M. Tiedtke, and J. F. Geleyn, 1981: A short history of the operational PBL parameterization at 
ECMWF. Workshop on Planetary Boundary Layer Parameterization, ECMWF, UK, 59-79.

McTaggart-Cowan, R., J. R. Gyakum, and M. K. Yau, 2001: Sensitivity testing of extratropical transitions using potential vorticity inversions to modify initial conditions: Hurricane Earl case study. Mon. Wea. Rev., 129, 1617-1636.

Moncrieff, M. W., D. E. Waliser, M. J. Miller, M. A. Shapiro, G. R. Asrar, and J. Caughey, 2012: Multiscale convective organization and the YOTC virtual global field campaign. Bull. Amer. Meteor. Soc., 93, 1171-1187.

Morgan, M. C., 1999: Using piecewise potential vorticity inversion to diagnose frontogenesis. Part I: A partitioning of the $\mathrm{Q}$ vector applied to diagnosing surface frontogenesis and vertical motion. Mon. Wea. Rev., 127, 2796-2821.

Murakami, M., 1990: Numerical modeling of dynamical and microphysical evolution of an isolated convective cloud - The 19 July 1981 CCOPE cloud. J. Meteor. Soc. Japan, 68, 107-128.

Murakami, M., T. L. Clark, and W. D. Hall, 1994: Numerical simulations of convective snow clouds over the Sea of Japan: Two-dimensional simulation of mixed layer development and convective snow cloud formation. $J$. Meteor. Soc. Japan, 72, 43-62.

Nguyen, H. V., and Y.-L. Chen, 2011: High-resolution initialization and simulations of Typhoon Morakot (2009). Mon. Wea. Rev., 139, 1463-1491.

Reynolds, R. W., N. A. Rayner, T. M. Smith, D. C. Stokes, and W. Wang, 2002: An improved in situ and satellite SST analysis for climate. J. Climate, 15, 1609-1625.

Segami, A., K. Kurihara, H. Nakamura, M. Ueno, I. Takano, and Y. Tatsumi, 1989: Operational mesoscale weather prediction with Japan Spectral Model. J. Meteor. Soc. Japan, 67, 907-924.

Shapiro, L. J., 1996: The motion of Hurricane Gloria: A potential vorticity diagnosis. Mon. Wea. Rev., 124, 2497-2508.

Smith, R. K., and M. T. Montgomery, 2016: The efficiency of diabatic heating and tropical cyclone intensification. Quart. J. Roy. Meteor. Soc., 142, 2081-2086.

Smith, R. K., M. T. Montgomery, and V. S. Nguyen, 2009: Tropical cyclone spin-up revisited. Quart. J. Roy. Meteor. Soc., 135, 1321-1335.

Tsuboki, K., and A. Sakakibara, 2002: Large-scale parallel computing of cloud resolving storm simulator. High Performance Computing. Zima, H. P., K. Joe, M. Sato, Y. Seo, and M. Shimasaki (eds.), Springer, 243259.

Tsuboki, K., and A. Sakakibara, 2007: Numerical prediction of high-impact weather systems. The textbook for seventeenth IHP training course in 2007. International Hydrological Programme. Hydrospheric Atmospheric Research Center, Nagoya University and UNESCO, 273 pp.

Waliser, D. E., M. W. Moncrieff, D. Burridge, A. H. Fink, D.
Gochis, B. N. Goswami, B. Guan, P. Harr, J. Heming, H.-H. Hsu, C. Jakob, M. Janiga, R. Johnson, S. Jones, P. Knippertz, J. Marengo, H. Nguyen, M. Pope, Y. Serra, C. Thorncroft, M. Wheeler, R. Wood, and S. Yuter, 2012: The "year" of tropical convection (May 2008-April 2010): Climate variability and weather highlights. Bull. Amer. Meteor. Soc., 93, 1189-1218.

Wang, C.-C., 2015: The more rain, the better the model performs - The dependency of quantitative precipitation forecast skill on rainfall amount for typhoons in Taiwan. Mon. Wea. Rev., 143, 1723-1748.

Wang, C.-C., G. T.-J. Chen, T.-C. Chen, and K. Tsuboki, 2005: A numerical study on the effects of Taiwan topography on a convective line during the mei-yu season. Mon. Wea. Rev., 133, 3217-3242.

Wang, C.-C., H.-C. Kuo, Y.-H. Chen, H.-L. Huang, C.-H. Chung, and K. Tsuboki, 2012: Effects of asymmetric latent heating on typhoon movement crossing Taiwan: The case of Morakot (2009) with extreme rainfall. $J$. Atmos. Sci., 69, 3172-3196.

Wang, C.-C., Y.-H. Chen, H.-C. Kuo, and S.-Y. Huang, 2013a: Sensitivity of typhoon track to asymmetric latent heating/rainfall induced by Taiwan topography: A numerical study of Typhoon Fanapi (2010). J. Geophys. Res.: Atmos., 118, 3292-3308.

Wang, C.-C., H.-C. Kuo, T.-C. Yeh, C.-H. Chung, Y.-H. Chen, S.-Y. Huang, Y.-W. Wang, and C.-H. Liu, 2013b: High-resolution quantitative precipitation forecasts and simulations by the Cloud-Resolving Storm Simulator (CReSS) for Typhoon Morakot (2009). J. Hydrol., 506, 26-41.

Wang, C.-C., H.-C. Kuo, R. H. Johnson, C.-Y. Lee, S.-Y. Huang, and Y.-H. Chen, 2015: A numerical study of convection in rainbands of Typhoon Morakot (2009) with extreme rainfall: Roles of pressure perturbations with low-level wind maxima. Atmos. Chem. Phys., 15, 11097-11115.

Wang, C.-C., S.-Y. Huang, S.-H. Chen, C.-S. Chang, and K. Tsuboki, 2016a: Cloud-resolving typhoon rainfall ensemble forecasts for Taiwan with large domain and extended range through time-lagged approach. Wea. Forecasting, 31, 151-172.

Wang, C.-C., G. T.-J. Chen, and K.-H. Ho, 2016b: A diagnostic case study of mei-yu frontal retreat and associated low development near Taiwan. Mon. Wea. Rev., 144, 2327-2349.

Wang, C.-C., B.-K. Chiou, G. T.-J. Chen, H.-C. Kuo, and C.-H. Liu, 2016c: A numerical study of back-building process in a quasistationary rainband with extreme rainfall over northern Taiwan during 11-12 June 2012. Atmos. Chem. Phys., 16, 12359-12382.

Wang, T.-C. C., Y.-S. Tang, C.-H. Wei, P.-L. Lin, and Y.-C. Liou, W.-Y. Chang, C.-B. Chou, B.-T. Ji, and C.-Y. Lin, 2010: The precipitation characteristics of Typhoon Morakot (2009) from radar analyses. Atmos. Sci., 38, 39-61 (in Chinese). 
Wu, C.-C., 2013: Typhoon Morakot: Key findings from the Journal TAO for improving prediction of extreme rains at landfall. Bull. Amer. Meteor. Soc., 94, 155-160.

Wu, C.-C., T.-H. Yen, Y.-H. Kuo, and W. Wang, 2002: Rainfall simulation associated with Typhoon Herb (1996) near Taiwan. Part I: The topographic effect. Wea. Forecasting, 17, 1001-1015.

Wu, L., J. Liang, and C.-C. Wu, 2011: Monsoonal influence on Typhoon Morakot (2009). Part I: Observational analysis. J. Atmos. Sci., 68, 2208-2221.

Xie, B., and F. Zhang, 2012: Impacts of typhoon track and island topography on the heavy rainfalls in Taiwan associated with Morakot (2009). Mon. Wea. Rev., 140, 3379-3394.

Yu, C.-K., and L.-W. Cheng, 2013: Distribution and mechanisms of orographic precipitation associated with Typhoon Morakot (2009). J. Atmos. Sci., 70, 2894-2915.

Zou, X., W. Huang, and Q. Xiao, 1998: A user's guide to the MM5 adjoint modeling system. NCAR Technical Note TN-437+1A. MMM division, National Center for Atmospheric Research, 92 pp.

Zou, X., and Q. Xiao, 2000: Studies on the initialization and simulation of a mature hurricane using a variational bogus data assimilation scheme. J. Atmos. Sci., 57, 836-860. 